\title{
LOS PROCESOS CONSTITUCIONALES COMO MEDIOS IDÓNEOS PARA LA EFECTIVIDAD DE LOS DERECHOS PROGRAMÁTICOS
}

\author{
LUIS ANdRÉS Roel Alva* \\ Universidad de Lima, Lima, Perú \\ Iroel@ulima.edu.pe \\ Ronny Rojas Álvarez** \\ Universidad Nacional Mayor de San Marcos, Lima, Perú \\ ronny.rojas@pucp.pe
}

Recibido: 12/10/2020 Aprobado: 19/10/2020

doi: https://doi.org/10.26439/iusetpraxis2021.n052.5018

\begin{abstract}
RESUMEN. La protección de los derechos económicos, sociales, culturales y ambientales (DESCA) a través de los procesos constitucionales cobra relevancia en un Estado constitucional de derecho, frente a la vulneración o amenaza de afectación por parte del Estado o de particulares. Decimos ello porque, en el desarrollo jurisprudencial del Tribunal Constitucional, se ha corroborado que dichos medios procesales son idóneos para garantizar tales derechos. Los citados pronunciamientos deben guardar coherencia y correspondencia con las sentencias expedidas por la Corte Interamericana de Derechos Humanos, considerando que, recientemente, se reconoció la justiciabilidad directa de los
\end{abstract}

\footnotetext{
*Abogado por la Pontificia Universidad Católica del Perú. Magíster en Derecho Constitucional por la misma casa de estudios. Máster en Derecho Constitucional por la Universidad de Castilla-La Mancha, España. Diplomado en Derechos Humanos y Derecho Internacional Humanitario por la American University Washington College of Law (Estados Unidos) en su Programa de Estudios Avanzados en Derechos Humanos y Derecho Internacional Humanitario. Diplomado de especialización en Justicia Constitucional, Interpretación y Tutela de los Derechos Fundamentales por la Universidad de Castilla-La Mancha, España. Es director fundador de la revista Estado Constitucional, docente de la Universidad de Lima y miembro de la Asociación Peruana de Derecho Constitucional.

** Abogado por la Universidad Nacional Mayor de San Marcos, con estudios concluidos en la maestría en Derecho Constitucional por la Pontificia Universidad Católica del Perú. Becario del X Curso Especializado para Funcionarios/as de Estado sobre utilización del Sistema Interamericano de Protección de Derechos Humanos, organizado por el Instituto Interamericano de Derechos Humanos en San José, Costa Rica. Es miembro de la revista Estado Constitucional y asistente de cátedra del profesor Luis Andrés Roel Alva en la Universidad de Lima.
} 
DESCA. Para ello, se analizó cuidadosamente la normativa y evolución jurisprudencial a nivel nacional y supranacional.

PALABRAS CLAVE: derechos económicos, sociales, culturales y ambientales / procesos constitucionales / justiciabilidad directa / Estado constitucional de derecho

\title{
CONSTITUTIONAL PROCESSES AS IDEAL MEANS FOR THE EFFECTIVENESS OF PROGRESSIVE RIGHTS
}

\begin{abstract}
The protection of economic, social, cultural and environmental rights (ESCER) through constitutional processes gains relevance in a constitutional rule of law in view of their possible violation or threat by the State or individuals. We hold this because, through the jurisprudential development of the Constitutional Court, it has been confirmed that those procedural means are suitable to guarantee said rights. The aforementioned pronouncements must be relevant to and consistent with the judgments issued by the Inter-American Court of Human Rights, considering that the direct justiciability of the ESCER has been recently recognized. To this end, the regulations and jurisprudential evolution at national and supranational level were carefully analyzed.
\end{abstract}

KEYWORDS: economic, social, cultural and environmental rights / constitutional processes / direct justiciability / constitutional rule of law 


\section{INTRODUCCIÓN}

El objetivo de este artículo es advertir la importancia de los procesos constitucionales como medios idóneos para garantizar y hacer cumplir los derechos económicos, sociales, culturales y ambientales (en adelante, DESCA), puesto que su fin más trascendente para los ciudadanos de los Estados constitucionales de derecho es garantizar la totalidad de los derechos fundamentales reconocidos dentro de nuestro ordenamiento jurídico'.

En este sentido, abordaremos temas como el modelo de Estado constitucional de derecho que hemos adoptado a partir de lo establecido en la obra del constituyente peruano, la Constitución Política de 1993, así como los procesos constitucionales encargados de garantizar sus contenidos, entre los cuales destacan los derechos fundamentales para cuya efectividad existen procesos específicos. Después de este marco teórico, expondremos cómo los DESCA, denominados también derechos programáticos, presentan particularidades esenciales que los diferencian del resto de derechos que poseen "efectividad directa"2, las cuales explicaremos a partir de la jurisprudencia del Tribunal Constitucional. Finalmente, en el último apartado y a partir de casos que forman parte de la jurisprudencia del precitado tribunal, desarrollaremos la tesis de esta ponencia, la cual es sustentar la relevancia de los procesos constitucionales en la protección de los derechos programáticos, siendo estos medios idóneos para alcanzar su efectividad.

\section{ESTADO CONSTITUCIONAL DE DERECHO, LOS PROCESOS CONSTITUCIONALES Y LA DEFENSA DE LOS DERECHOS FUNDAMENTALES EN EL ESTADO PERUANO}

\section{Nuestro Estado constitucional de derecho y los derechos fundamentales}

Antes de desarrollar el tema principal del presente artículo, consideramos necesario señalar, de modo preliminar, que en el Estado legal de derecho "[...] la Constitución no era entendida sino como una mera norma política carente de contenido jurídico vinculante y compuesta únicamente por una serie de disposiciones regulatorias de la labor de los poderes públicos" (Landa, 2011, p. 30). Sin embargo, tras el devenir hacia el vigente Estado constitucional de derecho, este modelo estatal tiene como fundamento que "[...] el concepto de Constitución ha transitado hasta un momento en el que ya no cabe duda de que la Constitución es la norma jurídica suprema del ordenamiento normativo nacional"

1 Código Procesal Constitucional, Ley N. ${ }^{\circ} 28237:$ "Artículo Il.- Fines de los procesos constitucionales. Son fines esenciales de los procesos constitucionales garantizar la primacía de la Constitución y la vigencia efectiva de los derechos constitucionales".

2 Conforme detallaremos en este artículo a partir de la sentencia en el caso Lagos del Campo vs. Perú emitida por la Corte Interamericana de Derechos Humanos el 31 de agosto del 2017, esta concepción inicial ha sido superada. 
(Landa, 2011, p. 30). Es así como el Tribunal Constitucional (en adelante, TC) ha declarado que nuestra Constitución Política es tanto una norma política como jurídica, y al ser la norma suprema dentro del ordenamiento jurídico peruano, vincula a todo ente público y a la sociedad en su conjunto ${ }^{3}$.

En este orden de ideas, resulta claro que "[...] si la Constitución tiene eficacia directa, no será solo norma sobre normas, sino norma aplicable; no será solo fuente sobre la producción, sino también fuente del derecho sin más" (De Otto, 1998, p. 76). De esta forma:

La Constitución es, pues, norma jurídica y, como tal, vincula. De ahí que, con acierto, pueda hacerse referencia a ella aludiendo al "derecho de la Constitución", esto es, al conjunto de valores, derechos y principios que, por pertenecer a ella, limitan y delimitan jurídicamente los actos de los poderes públicos. (De Otto, 1998, p. 76)

Se entiende, entonces, a la Constitución como la norma que sirve como parámetro y fuente para la creación del resto de ellas, así como la ley suprema dentro de nuestro ordenamiento jurídico, cuyos efectos se extienden a todas las ramas y especialidades del derecho, al ser sus principios y disposiciones de alcance general (Landa, 2013). Así pues, podemos establecer, citando lo pronunciado por el Supremo Intérprete de la Constitución ${ }^{4}$, lo siguiente:

[...] la supremacía normativa de la Constitución de 1993 se encuentra recogida en sus dos vertientes: tanto aquella objetiva, conforme a la cual la Constitución preside el ordenamiento jurídico (artículo 51), como aquella subjetiva, en cuyo

3 Sobre las implicancias del tránsito del Estado legal de derecho al Estado constitucional de derecho, nuestro Tribunal Constitucional ha declarado que "[...] supuso, entre otras cosas, abandonar la tesis según la cual la Constitución no era más que una mera norma política, esto es, una norma carente de contenido jurídico vinculante y compuesta únicamente por una serie de disposiciones orientadoras de la labor de los poderes públicos, para consolidar la doctrina conforme a la cual la Constitución es también una norma jurídica, es decir, una norma con contenido dispositivo capaz de vincular a todo poder (público o privado) y a la sociedad en su conjunto" (STC. Exp. N. ${ }^{\circ} 5854-$ 2005-PA/TC, 2005, fundamento jurídico 3).

4 Normativamente, esta categoría de Supremo Intérprete de la Constitución se encuentra expresamente determinada en la Ley Orgánica del Tribunal Constitucional, Ley N. ${ }^{\circ} 28301$; y en el Reglamento Normativo del Tribunal Constitucional, Resolución Administrativa N. ${ }^{\circ}$ 095-2004-P-TC.

- Ley Orgánica del Tribunal Constitucional, Ley N. ${ }^{\circ} 28301$.

"Artículo 1.- Definición

El Tribunal Constitucional es el órgano supremo de interpretación y control de la constitucionalidad. Es autónomo e independiente de los demás órganos constitucionales. Se encuentra sometido solo a la Constitución y a su Ley Orgánica. El Tribunal Constitucional tiene como sede la ciudad de Arequipa. Puede, por acuerdo mayoritario de sus miembros, tener sesiones descentralizadas en cualquier otro lugar de la República".

- Reglamento Normativo del Tribunal Constitucional, Resolución Administrativa N. ${ }^{\circ}$ 095-2004 -P-TC.

"Artículo 1.- Control e interpretación constitucional

El Tribunal Constitucional es el órgano supremo de interpretación y control de la Constitución. Es autónomo e independiente de los demás órganos constitucionales. Solo está sometido a la Constitución y a su Ley Orgánica". 
mérito ningún acto de los poderes públicos (artículo 45) o de la colectividad en general (artículo 38) puede vulnerarla válidamente. (STC. Exp. N. ${ }^{\circ}$ 5854-2005-PA/ TC, 2005, fundamento jurídico 6)

Por lo tanto, la Constitución Política como norma suprema, vigente y efectiva dentro de nuestro ordenamiento jurídico, vincula tanto a los entes y funcionarios públicos como a los particulares en todas sus acciones, no existiendo zona exenta de control constitucional ${ }^{5}$.

\section{Los procesos constitucionales y la tutela de las libertades}

Ahora bien, teniendo en cuenta que, en este modelo estatal de Estado constitucional de derecho - que fue asumido por nuestro constituyente para nuestro Estado, conforme determina el artículo 51 de nuestra Constitución Políticab -, “[...] el nuevo paradigma constitucional de los valores y principios [...] da sentido de unidad al orden jurídico, tanto para proteger los derechos fundamentales como para garantizar la supremacía jurídica constitucional" (Landa, 2013, p. 15). Así, la protección de la supremacía constitucional y la vigencia efectiva de los derechos fundamentales se encuentran a cargo de los procesos constitucionales establecidos en nuestra Norma Fundamental y desarrollados por el Código Procesal Constitucional, que en su artículo II los establece como sus fines ${ }^{7}$.

Asimismo, corresponde precisar que los procesos constitucionales responden a elementos característicos distintos del resto de procesos - denominados ordinariosdentro del ordenamiento jurídico, de manera que se convierten en extraordinarios respecto de estos últimos ${ }^{8}$. En este orden de ideas, el Supremo Intérprete de la Constitución

$5 \quad$ En relación con este tema, el Tribunal Constitucional ha declarado: "En efecto, afirmar que existen actos de alguna entidad estatal cuya validez constitucional no puede ser objeto de control constitucional supone sostener, con el mismo énfasis, que en tales ámbitos la Constitución ha perdido su condición de norma jurídica, para volver a ser una mera carta política referencial, incapaz de vincular al poder [cursivas añadidas]. Pretender que el Tribunal Constitucional se adhiera a esta tesis equivale a pretender que abdique del rol de guardián de la Constitución que el Poder Constituyente le ha confiado (artículo 201 de la Constitución). Tentativa que, como será sencillo de entender, jamás será de recibo en sede de este colegiado" (STC. Exp. N. ${ }^{\circ}$ 5854-2005-AA/TC, 2005, fundamento jurídico 7).

6 El artículo 51 de la Constitución Política dice: “La Constitución prevalece sobre toda norma legal; la ley, sobre las normas de inferior jerarquía, y así sucesivamente. La publicidad es esencial para la vigencia de toda norma del Estado".

7 Precisamente, el Tribunal Constitucional señala: “[E]l Código Procesal Constitucional (artículo II del Título Preliminar) ha establecido que los procesos constitucionales tienen como finalidad, por un lado, garantizar el principio jurídico de la supremacía constitucional (artículo 51 de la Constitución) $y$, por otro, preservar la observancia de la vigencia de los derechos fundamentales de la persona (artículo 10 de la Constitución)" (STC. Exp. N. ${ }^{\circ}$ 0266-2002-AA/TC, 2005, fundamento jurídico 5).

8 Al respecto, nuestro Tribunal Constitucional ha declarado: "Una primera diferencia radica en los fines que persiguen ambos tipos de procesos [cursivas añadidas]. En efecto, a diferencia de los procesos constitucionales, los procesos ordinarios no tienen como objetivo hacer valer el principio de supremacía de la Constitución, y no siempre persiguen la tutela de derechos fundamentales. La segunda diferencia estriba en la actuación del juez [cursivas añadidas]. En los procesos constitucionales, 
ha establecido que, en virtud de su autonomía procesal ${ }^{9}$ (Landa, 2009, p. 286), sus institutos procesales se encuentran alejados de las categorías clásicas del derecho procesal. Esto es así porque el derecho procesal constitucional en nuestro ordenamiento jurídico es un derecho constitucional concretizado: a diferencia de otros derechos procesales, que se sustentan en los principios y valores de la teoría general del proceso, el derecho procesal constitucional se fundamenta en la teoría constitucional, siendo una concretización de esta última ${ }^{10}$.

Esto mismo ha tenido en cuenta el legislador al momento de emitir el Código Procesal Constitucional, Ley $N{ }^{\circ} 28237$, el cual posee condición de ley orgánica, conforme determina el artículo 200 de nuestra Norma Fundamental ${ }^{11}$ y tiene como objeto desarrollar los contenidos constitucionales referidos a los procesos que esta reconoce y protege $\mathrm{e}^{12}$.

los jueces tienen - por razones más trascendentes que en los procesos ordinarios- el deber de controlar la actuación de las partes, a fin de conseguir, dentro de un plazo razonable, la tutela efectiva de los derechos fundamentales. La tercera se fundamenta en los principios que orientan los procesos constitucionales [cursivas añadidas]. Si bien es cierto que estos principios, nominalmente, son compartidos por ambos tipos de procesos, es indudable que la exigencia del cumplimiento de principios como de publicidad, economía procesal, socialización del proceso, impulso oficioso, elasticidad y de favor processum o pro actione, es fundamental e ineludible para el cumplimiento de los fines de los procesos constitucionales. Finalmente, la cuarta tiene que ver con la naturaleza de ambos procesos [cursivas añadidas], y que puede enunciarse básicamente en que, a diferencia de los ordinarios, los constitucionales son procesos de tutela de urgencia" (STC. Exp. N. ${ }^{\circ} 0266-$ 2002-AA/TC, 2005, fundamento jurídico 6).

9 El profesor César Landa (2009) señala que "[l]a autonomía procesal de los procesos constitucionales se asienta en la idea de la autonomía del derecho público, que tiene su razón de ser en la Constitución como norma suprema -lex legis- y como norma fuente de derecho - norma normarum-. De ella emana su fuerza normativa para, por un lado, subordinar las normas legales como los códigos procesales a los mandatos constitucionales, y, por otro lado, ser fuente de creación del derecho, es decir, principio y límite para la expedición de las normas legales y la jurisprudencia constitucional" (p. 286).

10 En este sentido, el Tribunal Constitucional ha explicado cómo debe entenderse el concepto de derecho constitucional concretizado: “[...], el C. P. Const. tiene que ser entendido como un derecho constitucional concretizado. Esto es, al servicio de la 'concretización' de la Constitución. Por ende, opera en beneficio de la interpretación de la Constitución en cada uno de los procesos constitucionales que el juez y el Tribunal Constitucional conocen con motivo de responder a una concreta controversia constitucional planteada. Por tal razón, esta concretización de la Constitución en cada controversia constitucional impone correlativamente que la hermenéutica de la norma procesal constitucional deba efectuarse conforme a una 'interpretación específicamente constitucional de las normas procesales constitucionales, una interpretación del Código Procesal Constitucional desde la Constitución' (Häberle habla de una 'interpretación de la Ley Orgánica del Tribunal Constitucional Federal -alemán- desde la Ley Fundamental'” (RTC. Exps. N. . 0025-2005-PI/TC y N. ${ }^{\circ}$ 0026-2005-PI/TC, acumulados, 2005, fundamento jurídico 15).

11 El artículo 200 de la Constitución Política dice: “Son garantías constitucionales: [...] Una ley orgánica regula el ejercicio de estas garantías y los efectos de la declaración de inconstitucionalidad o ilegalidad de las normas. [...]".

12 En este extremo, el Tribunal Constitucional ha declarado: "Las distintas áreas del derecho tienen un ámbito sustantivo y adjetivo en paridad de condiciones, tal como sucede, por ejemplo, en el derecho civil, donde la regulación procesal tiene la misma jerarquía que la existente a la sustantiva, pues tanto el Código Civil como el Código Procesal Civil tienen el rango de ley. Esto no sucede, por el 
En igual sentido, cabe señalar que, jurisprudencialmente, el TC ha configurado una tendencia en cuanto a privilegiar su autonomía procesal, lo cual conduce no solo a la adopción de institutos procesales "constitucionalizados", sino también a su creación jurisprudencial en directa relación con los fines de los procesos constitucionales ${ }^{13}$. Así, siendo uno de estos fines la protección de los derechos constitucionales frente a cualquier amenaza o afectación a los mismos ${ }^{14}$, el TC ha explicado su importancia dentro de nuestro Estado constitucional de derecho, sustentándose en la doble dimensión que poseen los procesos constitucionales (objetivo y subjetivo ${ }^{15}$ ). Hasta ha llegado a declarar:

La instauración de procesos específicos para la tutela de los derechos fundamentales ha constituido uno de los objetivos más importantes que la justicia constitucional ha conseguido. Ello se explica porque en los procesos constitucionales se busca no solo la protección de los derechos fundamentales, sino también la constitucionalidad del derecho objetivo. De ahí que se haya

contrario, en el ámbito constitucional. El Código Procesal Constitucional debe procedimentalizar las cuestiones sustantivas que se encuentran en la Constitución, norma que tiene claramente un nivel jerárquico superior, motivo por el cual, y tomando en cuenta el principio institucional de la interpretación conforme a la Constitución [...], el Código Procesal Constitucional debe ser entendido, comprendido y analizado de acuerdo con los contenidos existentes en la Norma Fundamental. Tan cierto es eso que los fines del proceso constitucional, que el propio Código reconoce en el artículo Il de su Título Preliminar, son la primacía constitucional y la protección de los derechos" (STC. Exp. N. ${ }^{\circ}$ 7873-2006-Al/TC, 2006, fundamento jurídico 7).

13 El Tribunal Constitucional dispuso la incorporación de la figura del litisconsorte facultativo en la Sentencia recaída en los Exps. N. ${ }^{\circ}$ 0020-2005-PI/TC y N. ${ }^{\circ}$ 0021-2005-PI/TC, acumulados, fundamento jurídico 2. También el mismo Tribunal señaló que, “[...] en aplicación del principio de autonomía procesal, este tribunal incorpora en la presente resolución la figura del 'partícipe' en el proceso de inconstitucionalidad, en cuanto sujeto procesal del mismo, respecto a las personas que no son parte demandante ni demandada" (RTC. Exps. N. ${ }^{\circ} 0025-2005-\mathrm{PI} / \mathrm{TC}$ y N. ${ }^{\circ} 0026-2005-\mathrm{PI} /$ TC, acumulados, 2005, fundamento jurídico 22). Por último, respecto a la incorporación del "partícipe", el propio TC ha señalado que, “[...] en aplicación del principio de autonomía procesal, este tribunal considera que el partícipe debe ser notificado de la demanda y de la contestación, pudiendo presentar informe escrito, así como intervenir en la vista de la causa para sustentar el informe oral si es que así lo estimara por conveniente. Siendo la razón y propósito de su intervención enriquecer el proceso interpretativo en la controversia, es su intervención en la vista de la causa el momento estelar y trascendental de su actuación. Por esta razón, su intervención no debe ocasionar el entorpecimiento del procedimiento y de las actuaciones procesales ordenadas por el Tribunal Constitucional en su condición de director del proceso" (RTC. Exp. N. ${ }^{\circ}$ 0033-2005-AI/TC, 2006, fundamento jurídico 3).

14 Código Procesal Constitucional, Ley N. ${ }^{\circ} 28237$ : “Artículo 1.- Finalidad de los procesos. Los procesos a los que se refiere el presente título [procesos de habeas corpus, amparo, habeas data y cumplimiento] tienen por finalidad proteger los derechos constitucionales, reponiendo las cosas al estado anterior a la violación o amenaza de violación de un derecho constitucional, o disponiendo el cumplimiento de un mandato legal o de un acto administrativo. [...]".

15 Sobre esta doble dimensión de los procesos constitucionales, el Tribunal Constitucional ha declarado: "Todos los procesos constitucionales (incluyendo aquellos orientados a la tutela de derechos fundamentales) gozan de una dimensión objetiva orientada a preservar el orden constitucional como una suma de valores institucionales" (STC. Exp. N. ${ }^{\circ} 0005-2005-C C / T C$, fundamento jurídico 7). 
señalado que dichos procesos deben ser capaces de comprender no solo la tutela subjetiva de los derechos constitucionales, sino también la tutela objetiva de la Constitución. (STC. Exp. N. ${ }^{\circ}$ 0266-2002-AA/TC, 2005, fundamento jurídico 5)

A modo de conclusión, debemos señalar que los procesos constitucionales tienen como finalidad garantizar la supremacía de la Constitución Política, en cuanto norma suprema de nuestro ordenamiento jurídico, así como proteger los derechos que poseen reconocimiento constitucional, frente a cualquier amenaza y afectación. Estos últimos tienen una especial relevancia, puesto que protegen al ciudadano frente a cualquier arbitrariedad de los entes estatales y de los particulares, que limite o afecte sus derechos ${ }^{16}$.

\section{LOS DERECHOS PROGRAMÁTICOS Y SUS PARTICULARIDADES A PARTIR DE LA JURISPRUDENCIA DEL TRIBUNAL CONSTITUCIONAL}

\section{Los derechos económicos, sociales, culturales y ambientales (DESCA)}

Suárez Sebastián (2009) señala que, en principio, debemos precisar que los derechos económicos, sociales, culturales y ambientales (en adelante, DESCA):

[...] se refieren a aspectos fundamentales en la vida de las personas, que tienen que ver con el desarrollo de condiciones básicas de la dignidad humana como la posibilidad de tener un nivel de vida adecuado. Dentro de estos se encuentran derechos como la educación, la vivienda, la alimentación, la salud y el trabajo, entre otros. (p. 62)

De esa manera, "[...] la estructura de los [DESCA] se caracterizaría por obligar al Estado a hacer, es decir, a brindar prestaciones positivas: proveer servicios de salud, asegurar la educación" (Abramovich y Courtis, 1997, p. 2), por lo que "[p]uede reconocerse que la faceta más visible de los [DESCA] son las obligaciones de hacer, y es por ello que se los denomina derechos-prestación" (Abramovich y Courtis, 1997, p. 4). En otras palabras, requieren para su realización "[...] de medidas, acciones, prestaciones, servicios, que la persona, por sí misma, no puede asegurar" (Clérico, Ronconi y Aldao, 2013, p. 90).

Ahora bien, para que los DESCA tengan una real efectividad, no deben agotarse solamente en su mención en los acuerdos internacionales o en el reconocimiento que hagan

16 En esta parte, cabe recordar lo expuesto por el profesor Ernesto Blume Fortini (2011), a manera de aproximación al concepto de proceso constitucional en nuestro ordenamiento jurídico constitucional: “[...] el proceso constitucional [...] es aquel conjunto dialéctico de actos, ejecutados con sujeción a determinadas reglas, que instrumentaliza a través de órganos que ejercen la jurisdicción constitucional, la solución de un conflicto de naturaleza constitucional, surgido sea por la amenaza o violación de los derechos humanos, o fundamentales, sea por el ejercicio indebido de la facultad normativa del Estado, sea por la afectación en forma activa o pasiva de las competencias o atribuciones asignadas a los órganos de rango constitucional, sea, en general, por la violación de la normativa constitucional en sentido estricto" (p. 228). 
los Estados Partes, sino que requieren de acciones concretas que garanticen su cumplimiento. En esa línea argumentativa, consideramos pertinente señalar:

Los derechos reconocidos en pactos como el Pacto Internacional de Derechos Económicos, Sociales y Culturales y otros tratados establecen una serie de garantías de los [DESCA] para las comunidades y las personas. Eso significa que los Estados hacen un reconocimiento jurídico de tales derechos, lo que implica obligaciones con las que deben cumplir. Este reconocimiento, a su vez, establece una relación entre dos partes: los titulares de los derechos y el ente encargado de satisfacer su cumplimiento, en este caso los Estados. (Clérico et al., 2013, p. 76)

Así, el reconocimiento de los DESCA implica diversas obligaciones por parte de los Estados, como son las siguientes:

[...]

1. Respetar: esta obligación se refiere a que los Estados deben abstenerse de tomar medidas que obstaculicen o impidan el goce de los derechos humanos, lo que quiere decir que el Estado no debe destruir los estándares alcanzados. Esto implica para los Estados obligaciones negativas, pues les dice lo que no deben hacer (por ejemplo, no impedir que la gente se eduque).

2. Proteger: es una obligación de carácter positivo, pues exige a los Estados actuar y no abstenerse de hacerlo. Además, les exige medidas que impidan que terceros obstaculicen el disfrute de un estándar de derecho y afecten la calidad de vida de las personas.

3. Realizar: es otra obligación positiva para los Estados en cuanto al cumplimiento de los estándares de derechos humanos, y se refiere a las medidas que deben tomar para cumplir y satisfacer los derechos. Tales medidas pueden ser de carácter legislativo, administrativo, presupuestal, judicial, social, educativas, entre otras. (Clérico et al., 2013, p. 77)

A estas obligaciones generales, es necesario añadir otras más específicas:

[...] los Estados tienen otras [obligaciones] más específicas, como la de no discriminación, la cual establece que los [DESCA] son inherentes a todas las personas y no puede haber exclusiones o distinciones para su reconocimiento y cumplimiento por parte del Estado por razones de raza, género, origen social, opinión política y otras. (Clérico et al., 2013, p. 77)

Conforme a lo expuesto, el desarrollo y protección de los DESCA no se limita a la invocación de los tratados supranacionales ${ }^{17}$, sino también a la jurisprudencia de los

17 Sobre este punto consideramos relevante señalar que "[...] podemos decir que el Estado peruano se encuentra comprometido al irrestricto cumplimiento de las disposiciones contenidas en los TIDH [Tratados Internacionales de Derechos Humanos]. Además, hemos dado cuenta de que los acuerdos internacionales sobre derechos humanos asumidos por el Estado peruano poseen rango constitucional dentro de nuestro sistema normativo y, por lo tanto, también los derechos que estos 
organismos internacionales ${ }^{18}$ y del Tribunal Constitucional, como desarrollaremos posteriormente.

\section{Los DESCA a partir de la jurisprudencia del Tribunal Constitucional}

Los DESCA pueden identificarse en nuestra vida cotidiana a partir del reconocimiento de aquellas condiciones fundamentales que nos hacen falta o que requerimos para vivir de manera plena, es decir, aquellas condiciones que cuando se cumplen le permiten al ser humano su realización en condiciones dignas (Sandoval, 2001, p. 52). Para ejemplificar esto último, desarrollaremos los derechos constitucionales que forman parte de los DESCA, como son los derechos a la salud, a la educación, a la pensión y a la seguridad social, a un medio ambiente equilibrado y adecuado para el desarrollo de la persona humana, y a la alimentación.

El TC es considerado actualmente como el Supremo Intérprete de la Constitución, dado que sus decisiones judiciales interpretan, de manera suprema, el contenido de las normas constitucionales (Landa, 2011, p. 13) a fin de garantizar la protección de los derechos fundamentales y la supremacía constitucional, en concordancia con los Tratados Internacionales de Derechos Humanos (en adelante, TIDH) de los que el Estado peruano forma parte ${ }^{19}$.

En cuanto a los DESCA, el TC ha establecido que son derechos fundamentales, al igual que los denominados civiles y políticos (Rubio, 2013, p. 204), en tanto:

Si bien los DESC son derechos fundamentales, tienen la naturaleza propia de un derecho público subjetivo, antes que la de un derecho de aplicación directa. Lo cual

reconocen ostentan dicho rango normativo. Y esto último es significativo destacar porque, acorde a lo que hemos indicado previamente, el Estado peruano ya en una época ha negado la competencia jurisdiccional de la Corte IDH, así como también la vinculatoriedad de las disposiciones contenidas en la CADH, lo cual, conforme hemos expresado, es imposible de sostener jurídicamente en la actualidad" (Roel Alva y Huayta Alipio, 2018, p. 702).

18 En relación con la jurisprudencia supranacional acerca de los derechos económicos, sociales, culturales y ambientales (DESCA), citamos al profesor Juan Méndez (2004), quien señala: “El disfrute de los derechos económicos, sociales y culturales en el continente americano se caracteriza por condiciones de desigualdad en el acceso a recursos y servicios que garanticen y protejan estos derechos. En tales condiciones, los aportes del sistema interamericano de protección no han sido, hasta el momento, significativos - al menos en comparación con la rica experiencia desarrollada en relación con los derechos civiles y políticos-, pero ha comenzado un proceso que permite abrigar esperanzas de una mayor incidencia en los próximos años [cursivas añadidas]" (p. 115).

19 El profesor Juan Méndez (2004), haciendo un reconocimiento a las jurisdicciones internas de cada Estado en su relevante rol de protección de los DESCA, afirma: “Afortunadamente, en las jurisdicciones nacionales de nuestros países (y también de otras democracias emergentes, como India y Sudáfrica) comienza a abrirse camino una jurisprudencia que, sin desechar el contenido de la norma sobre realización progresiva, diseña procesos mediante los cuales el poder administrador debe dar cuenta detallada de sus esfuerzos de buena fe por dar cumplimiento a normas de derechos sociales incluidas en las constituciones o en tratados internacionales. Un ejercicio similar es el que está haciendo el sistema interamericano" (p. 143). 
no significa que sean "creación" del legislador. En tanto derechos fundamentales, son derechos de la persona reconocidos por el Estado y no otorgados por este [cursivas añadidas]. Sin embargo, su reconocimiento constitucional no es suficiente para dotarlos de eficacia plena, pues su vinculación jurídica solo queda configurada a partir de su regulación legal, la que los convierte en judicialmente exigibles. Por ello, en la Constitución mantienen la condición de una declaración jurídica formal, mientras que la ley los convierte en un mandato jurídico aprobatorio de un derecho social. (STC. Exp. N. ${ }^{\circ}$ 1417-2005-PA/TC, 2005, fundamento jurídico 14)

En este orden de ideas, los DESCA "[...] representan los fines sociales del Estado a través de los cuales el individuo puede lograr su plena autodeterminación" (STC. Exp. N. 2016-2004-AA/TC, 2004, fundamento jurídico 9). Así, para lograr su efectividad, es necesaria:

[...] la actuación del Estado a través del establecimiento de servicios públicos, así como de la sociedad mediante la contribución de impuestos, ya que toda política social necesita de una ejecución presupuestal; también lo es que estos derivan en obligaciones concretas por cumplir, por lo que los Estados deben adoptar medidas constantes y eficaces para lograr progresivamente la plena efectividad de los mismos en igualdad de condiciones para la totalidad de la población. (STC. Exp. N. 1417-2005-PA/TC, 2005, fundamento jurídico 16)

Por último, es relevante citar lo declarado por el TC respecto de la revaloración de los deberes de solidaridad, en los cuales se sustentan los DESCA, los cuales deben ser entendidos como verdaderos mandatos constitucionales para el Estado peruano. Al respecto, ha señalado:

Entonces, los derechos sociales deben interpretarse como verdaderas garantías del ciudadano frente al Estado dentro de una visión que busca revalorar la eficacia jurídica de los mandatos constitucionales y, por ende, la vigencia de la Constitución. Así, en algunos casos han sido planteados, incluso, como deberes de solidaridad que involucran no solo obligaciones del Estado, sino de toda la sociedad [...]. (STC. Exp. N. ${ }^{\circ}$ 2016-2004-AA/TC, 2004, fundamento jurídico 12)

En conclusión, a partir de lo expresado hasta ahora, podemos decir que

[...] el planteamiento del TC se aleja de consignas ideológicas tradicionales, para introducirse en una especie de activismo en favor de la atención de los derechos fundamentales bajo una visión integral que tiene como objetivo no solo la defensa de la persona humana y el respeto de su dignidad como el fin supremo del Estado, sino también la propia defensa de este último. (Rubio, 2013, p. 206)

Por tanto, podemos cerrar este apartado afirmando que, a partir de dicho activismo reflejado en su desarrollo jurisprudencial, el TC ha venido evaluando y analizando los DESCA, dado que tienen la misma naturaleza jurídica que el resto de los derechos fundamentales, con la precisión de que "[...] en tanto derechos subjetivos de los particulares y obligaciones mediatas del Estado, necesitan de un proceso de ejecución de políticas 
sociales para que el ciudadano pueda gozar de ellos o ejercitarlos de manera plena" (Rubio, 2013, p. 210).

\section{Principales particularidades de los DESCA}

No son derechos de cumplimiento directo e inmediato

La tradicional distinción entre los DESCA y los derechos civiles y políticos es que los primeros son de cumplimiento programático. Este aspecto ha sido materia de análisis por parte del TC, que señala:

[...] los DESC son derechos fundamentales, tienen la naturaleza propia de un derecho público subjetivo, antes que la de un derecho de aplicación directa. Lo cual no significa que sean "creación" del legislador. En tanto derechos fundamentales, son derechos de la persona reconocidos por el Estado y no otorgados por este. (STC. Exp. N. ${ }^{\circ} 1417-2005-P A / T C, 2005$, fundamento jurídico 14)

Asimismo, el citado tribunal ha declarado que

[...] la distinta eficacia que presentan los derechos fundamentales entre sí no solo reposa en cuestiones teóricas de carácter histórico, sino que estas diferencias revisten significativas repercusiones prácticas. En tal sentido, cabe distinguir los derechos de preceptividad inmediata o autoaplicativos, de aquellos otros denominados prestacionales, de preceptividad diferida, progresivos o programáticos. (STC. Exp. N. ${ }^{\circ}$ 1417-2005-AA/TC, 2005, fundamento jurídico 13)

De igual modo, el TC manifiesta que a la categoría de derechos programáticos:

[...] pertenecen los derechos fundamentales económicos, sociales y culturales (DESC) que, en tanto derechos subjetivos de los particulares y obligaciones mediatas del Estado, necesitan de un proceso de ejecución de políticas sociales para que el ciudadano pueda gozar de ellos o ejercitarlos de manera plena. Tal es el sentido de la Undécima Disposición Final y Transitoria (UDFT) de la Constitución, al establecer que "[l]as disposiciones de la Constitución que exijan nuevos y mayores gastos públicos se aplican progresivamente". (STC. Exp. N. ${ }^{\circ}$ 1417-2005-AA/TC, 2005, fundamento jurídico 13)

A partir del desarrollo jurisprudencial del TC, se advierte que la diferenciación que tradicionalmente ha existido entre los derechos civiles y políticos y los DESCA se basa en la eficacia inmediata para los primeros y mediata para estos últimos. Sin embargo, igualmente se requiere una mínima satisfacción "[...] indispensable para el goce de los derechos civiles y políticos" (STC. Exp. N. ${ }^{\circ} 2945-2003-A A / T C, 2004$, fundamento jurídico 11), porque, como hemos explicado líneas arriba, la satisfacción de estos derechos importa para que la ciudadanía posea los mínimos necesarios para una vida digna. 


\section{Principio de progresividad y no regresividad}

Consideramos pertinente, para contextualizar este apartado, citar el artículo 26 de la Convención Americana sobre Derechos Humanos (en adelante, CADH), que prescribe lo siguiente:

Los Estados Partes se comprometen a adoptar providencias, tanto a nivel interno como mediante la cooperación internacional, especialmente económica y técnica, para lograr progresivamente la plena efectividad de los derechos que se derivan de las normas económicas, sociales y sobre educación, ciencia y cultura, [...] en la medida de los recursos disponibles, por vía legislativa u otros medios apropiados.

De igual forma, de acuerdo con el artículo 2 del Pacto Internacional de Derechos Económicos, Sociales y Culturales (en adelante, PIDESC):

Cada uno de los Estados Partes en el presente pacto se compromete a adoptar medidas, tanto por separado como mediante la asistencia y la cooperación internacionales, especialmente económicas y técnicas, hasta el máximo de los recursos de que disponga, para lograr progresivamente, por todos los medios apropiados, inclusive en particular la adopción de medidas legislativas, la plena efectividad de los derechos aquí reconocidos.

En las precitadas disposiciones internacionales, se puede advertir el reconocimiento al principio de progresividad de los derechos económicos, sociales y culturales -y actualmente también los ambientales-, lo cual obliga a los Estados Partes de estos $\mathrm{TIDH}^{20}$ a garantizar la progresividad de estos. De ahí se desprende como consecuencia la prohibición de regresividad de ellos ${ }^{21}$.

20 Al respecto, sobre la obligación del Estado peruano de cumplir con las disposiciones contenidas en los TIDH respecto de los cuales es parte, el Tribunal Constitucional ha concluido, a partir de la lectura e interpretación de diferentes disposiciones constitucionales, que "[l]os tratados internacionales sobre derechos humanos no solo conforman nuestro ordenamiento, sino que, además, detentan rango constitucional. El Tribunal Constitucional ya ha afirmado al respecto que dentro de las 'normas con rango constitucional' se encuentran los 'Tratados de derechos humanos'" (STC. Exps. N. ${ }^{\circ} 0025-2005-\mathrm{PI} / \mathrm{TC}_{\text {y N }}{ }^{\circ}$ 0026-2005-PI/TC, 2006, acumulados, fundamento jurídico 26).

21 De acuerdo con la Corte Interamericana de Derechos Humanos: "El Tribunal observa que el desarrollo progresivo de los derechos económicos, sociales y culturales ha sido materia de pronunciamiento por parte del Comité de Derechos Económicos, Sociales y Culturales de las Naciones Unidas, en el sentido de que la plena efectividad de aquellos 'no podrá lograrse en un breve período de tiempo' y que, en esa medida, 'requiere un dispositivo de flexibilidad necesaria que refleje las realidades del mundo [...] y las dificultades que implica para cada país el asegurar [dicha] efectividad'. En el marco de dicha flexibilidad en cuanto a plazo y modalidades, el Estado tendrá esencialmente, aunque no exclusivamente, una obligación de hacer, es decir, de adoptar providencias y brindar los medios y elementos necesarios para responder a las exigencias de efectividad de los derechos involucrados, siempre en la medida de los recursos económicos y financieros de que disponga para el cumplimiento del respectivo compromiso internacional adquirido. Así, la implementación progresiva de dichas medidas podrá ser objeto de rendición de cuentas y, de ser el caso, el cumplimiento del respectivo compromiso adquirido por el Estado podrá ser exigido ante las instancias llamadas a resolver eventuales violaciones a los derechos humanos. Como correlato 
Ferrer McGregor, Morales Antoniazzi y Flores Pantoja (2018) explican que, de acuerdo con lo expuesto, en relación con el principio de progresividad y la forma como debe cumplirse por parte de los Estados:

[...] una interpretación errónea de la obligación de progresividad es que, si bien esta implica un largo período de tiempo (o progresivamente), no es sinónimo de inacción que dejaría sin contenido a la obligación; por el contrario, dicha obligación debe interpretarse en el sentido de ser un objetivo general, la razón de ser del Pacto, que es establecer claras obligaciones para los Estados Partes con respecto de la plena efectividad de los derechos de que se trata. (p. 21)

\section{En esta misma línea de argumentación, nuestro TC ha declarado que}

[...] debe tenerse presente que el concepto de progresividad constituye un concepto netamente objetivo y no subjetivo, motivo por el cual el análisis de las eventuales regresiones que en materia de seguridad social realice el Estado no pueden ser analizadas a la luz de un grupo de pensionistas no representativos de la situación que afronta el Estado en dicha materia. (STC. Exps. N. ${ }^{\circ} 0001-2004-\mathrm{Al} / \mathrm{TC}$ y N. ${ }^{\circ}$ 0002-2004-Al/TC, acumulados, 2004, fundamento jurídico 56)

Por otro lado, respecto al principio de no regresividad, el mismo TC ha determinado:

Esta afirmación permite sostener que el concepto de progresividad no supone absoluta imposibilidad de regresión en los avances efectuados por el Estado en materia de derechos sociales, en la medida que ello quede plenamente justificado considerando atención a la totalidad de los recursos que disponga el Estado, y siempre que existan razones de interés social que así lo impongan. (STC. Exps. N. ${ }^{\circ} 0001-2004-A I / T C$ y N. ${ }^{\circ} 0002-2004-A I / T C$, acumulados, 2004 , fundamento jurídico 55)

Más adelante, este mismo tribunal concluyó:

Sobre el principio de progresividad de los derechos con contenido prestacional, el Tribunal Constitucional peruano pone especial énfasis en el tema de la no regresividad como un límite efectivo a la discrecionalidad de la autoridad en materia de políticas públicas. Además, pone de manifiesto que la progresividad no solo

de lo anterior, se desprende un deber - si bien condicionado- de no-regresividad, que no siempre deberá ser entendido como una prohibición de medidas que restrinjan el ejercicio de un derecho. Al respecto, el Comité de Derechos Económicos, Sociales y Culturales de las Naciones Unidas ha señalado que 'las medidas de carácter deliberadamente regresivo en este aspecto requerirán la consideración más cuidadosa y deberán justificarse plenamente por referencia a la totalidad de los derechos previstos en el Pacto [Internacional de Derechos Económicos, Sociales y Culturales] y en el contexto del aprovechamiento pleno del máximo de los recursos de que [el Estado] disponga'. En la misma línea, la Comisión Interamericana ha considerado que para evaluar si una medida regresiva es compatible con la Convención Americana, se deberá 'determinar si se encuentra justificada por razones de suficiente peso'. Por todo lo expuesto, cabe afirmar que la regresividad resulta justiciable cuando de derechos económicos, sociales y culturales se trate" (Corte Interamericana de Derechos Humanos [Corte IDH], 2009, párrs. 102-103). 
dice relación [sic] con aspectos cuantitativos, sino también cualitativos o de calidad de los servicios entregados para el cumplimiento de la garantía de derechos humanos. (Nash Rojas, 2011, p. 93)

De lo señalado, podemos establecer que el TC considera a los DESCA como derechos fundamentales "[...] de cumplimiento programático frente a los últimos de cumplimiento inmediato [...], pero con algunas variantes significativas" (Nash Rojas, 2011, p. 93). Por eso, el Supremo Colegiado:

[...] recoge esta complejidad y se desenvuelve dentro de la doble faceta que exige el tratamiento de los DESC: por un lado, consisten en derechos subjetivos de la persona y, por otro, se presentan como obligaciones que el Estado debe cumplir [sic], pero de manera mediata, lo que significa de manera próxima, cercana, no lejana y no diferida en el tiempo sin apremio. (Rubio, 2013, p. 212)

Pero sin dejar de exigir un mínimo cumplimiento de dichos derechos, de acuerdo con los TIDH de los que el Perú forma parte.

\section{Exigibilidad por parte del Estado y políticas públicas}

En cuanto a la particularidad de su exigencia de cumplimiento por parte del Estado peruano, la Corte Interamericana de Derechos Humanos (en adelante, Corte IDH) declaró en su momento que este, al igual que los Estados Partes de la CADH, deberá adoptar los medios y elementos necesarios para responder a las exigencias de la ciudadanía en aras de cumplir con la efectividad de los DESCA, siendo esta exigencia flexible en lo que se refiere al plazo y modalidades de realización ${ }^{22}$.

Asimismo, el TC ha señalado que los DESCA exigen al Estado peruano una intervención concreta, dinámica y eficiente, puesto que su efectividad permite asegurar a la ciudadanía condiciones mínimas para una vida digna:

[...] en el Estado social y democrático de derecho, la ratio fundamentalis no puede ser privativa de los denominados derechos de defensa, es decir, de aquellos derechos cuya plena vigencia se encuentra, en principio, garantizada con una conducta estatal abstencionista, sino que es compartida también por los derechos de prestación que reclaman del Estado una intervención concreta, dinámica y eficiente, a

22 Al respecto, la Corte IDH establece: “El Tribunal también ha determinado que en el marco de dicha flexibilidad en cuanto al plazo y modalidades de realización, el Estado tendrá esencialmente, aunque no exclusivamente, una obligación de hacer, es decir, de adoptar providencias y brindar los medios y elementos necesarios para responder a las exigencias de efectividad de los derechos involucrados, siempre en la medida de los recursos económicos y financieros de que disponga para el cumplimiento del respectivo compromiso internacional adquirido. Así, la implementación progresiva de dichas medidas podrá ser objeto de rendición de cuentas y, de ser el caso, el cumplimiento del respectivo compromiso adquirido por el Estado podrá ser exigido ante las instancias llamadas a resolver eventuales violaciones a los derechos humanos" (Corte IDH, 2018, párr. 142). 
efectos de asegurar las condiciones mínimas para una vida acorde con el principioderecho de dignidad humana. (STC. Exp. N. ${ }^{\circ}$ 1417-2005-PA/TC, 2005, fundamento jurídico 19)

Por otro lado, el TC señala que la exigencia de un DESCA no debe reducirse a la necesidad de una regulación legal, puesto que en sus palabras:

[...], sostener que los derechos sociales se reducen a un vínculo de responsabilidad política entre el constituyente y el legislador, no solo es una ingenuidad en cuanto a la existencia de dicho vínculo, sino también una distorsión evidente en cuanto al sentido y coherencia que debe mantener la Constitución [...]. En consecuencia, la exigencia judicial de un derecho social dependerá de factores tales como la gravedad y razonabilidad del caso, su vinculación o afectación de otros derechos y la disponibilidad presupuestal del Estado, siempre y cuando puedan comprobarse acciones concretas de su parte para la ejecución de políticas sociales. (STC. Exp. N. ${ }^{\circ}$ 2945-2003-AA/TC, 2004, fundamentos jurídicos 18 y 33)

Es así en atención a que los DESCA, en cuanto “[...] derechos subjetivos de los particulares y obligaciones mediatas del Estado, necesitan de un proceso de ejecución de políticas sociales para que el ciudadano pueda gozar de ellos o ejercitarlos de manera plena" (STC. Exp. N. ${ }^{\circ} 1417-2005-P A / T C, 2005$, fundamento jurídico 13), e inclusive como lo señala la Comisión Interamericana de Derechos Humanos (en adelante, $\mathrm{CIDH}$ ):

[E]s fundamental que el enfoque de derechos humanos en su indivisibilidad se aplique en todas las etapas de construcción de las políticas públicas. Esto parte por afirmar la voluntad política de todos los poderes estatales que, en cumplimiento de los compromisos asumidos con la Comunidad Internacional, como sobre todo con sus sociedades, aseguren que los Estados organizan sus aparatos para asegurar la máxima movilización de recursos, en favor de la progresividad y no regresividad en derechos. Ancladas en el principio de indivisibilidad y progresividad de los derechos humanos, las políticas públicas en DESCA son una herramienta indispensable para la reducción de las desigualdades. De esa manera contribuyen a la construcción de sociedades más justas y democráticas. (Comisión Interamericana de Derechos Humanos [CIDH], 2018, p. 62)

No podemos dejar de recalcar la necesidad de que cada funcionario, especialmente aquellos responsables de fijar y desarrollar las políticas públicas respecto a dichos derechos, ha de hacerlo conforme no solo a los tratados internacionales sobre la materia, sino también sobre los lineamientos anteriormente expuestos.

\section{Justiciabilidad y medios de protección}

La justiciabilidad de los DESCA se define como aquella potestad que faculta a acudir a mecanismos formales y judiciales para lograr la protección de estos derechos; es decir, son las acciones que buscan la defensa de derechos violados ante tribunales o instancias administrativas adecuadas (Sandoval, 2001). Cabe señalar, además, que “[...] dada 
su compleja estructura, no existe [DESCA] que no presente al menos alguna característica o faceta que permita su exigibilidad judicial en caso de violación" (Abramovich y Courtis, 1997, p. 16).

Así pues, siguiendo a los mencionados autores, de modo inicial, esta justiciabilidad podía concretarse de dos modos: “(i) directa: el objeto de la actuación judicial tiene como sustento la invocación directa de un derecho económico, social o cultural; (ii) indirecta: la tutela o protección del derecho social se logra por la invocación de un derecho distinto" (Abramovich y Courtis, 1997, p. 16). En este orden de ideas, agregan:

[...] si bien los principales [DESCA] han sido consagrados en el plano internacional en numerosos instrumentos, su reconocimiento universal como auténticos derechos no se alcanzará hasta superar los obstáculos que impiden su adecuada justiciabilidad, entendida como la posibilidad de reclamar ante un juez o tribunal de justicia el cumplimiento al menos de algunas de las obligaciones que constituyen el objeto del derecho. (Abramovich y Courtis, 1997, p. 11)

De igual modo, identificamos la conveniencia de contar con mecanismos procesales idóneos, a fin de salvaguardar los referidos derechos, por eso:

[L]ejos de constituir una cuestión cerrada, la adecuación de los mecanismos procesales para hacer que el Estado cumpla con derechos económicos, sociales y culturales por vía judicial requiere un esfuerzo imaginativo que involucre nuevas formas de utilización de mecanismos procesales tradicionales; la expandida consideración de los derechos económicos, sociales y culturales como derechos; un cierto activismo judicial, que incluya una dosis de creatividad pretoriana; y la propuesta legislativa de nuevos tipos de acciones capaces de vehiculizar reclamos colectivos y demandas de alcance general frente a los poderes públicos. (Abramovich y Courtis, 1997, p. 16)

En mérito a lo señalado, podemos establecer que, a partir de lo determinado en el caso Lagos del Campo vs. Perú (Corte IDH, 2017) ${ }^{23}$, se dispuso lo siguiente:

[Que se] diera el paso hacia darle plena fuerza normativa a la Convención Americana y se declarara la justiciabilidad directa [cursivas añadidas] de su artículo 26 , no solo en su faceta de progresividad, sino también en sus componentes asociados a las obligaciones de respeto y garantía de los DESCA. (Parra Vera, 2018, p. 230)

23 Efectivamente, la Corte IDH (2017) determinó: "Finalmente, cabe señalar que la Corte ha establecido previamente su competencia para conocer y resolver controversias relativas al artículo 26 de la Convención Americana, como parte integrante de los derechos enumerados en la misma, respecto de los cuales el artículo 1.1 confiere obligaciones generales de respeto y garantía a los Estados (supra párr. 142). Asimismo, la Corte ha dispuesto importantes desarrollos jurisprudenciales en la materia, a la luz de diversos artículos convencionales. En atención a estos precedentes, con esta Sentencia se desarrolla y concreta una condena específica por la violación del artículo 26 de la Convención Americana sobre Derechos Humanos, dispuesto en el Capítulo III, titulado Derechos Económicos, Sociales y Culturales de este tratado" (párr. 154). 
Por tanto, se está superando la deuda pendiente del Sistema Interamericano de Protección de Derechos Humanos respecto a los DESCA (Parra Vera, 2018). Esa influencia también implica "[...] que el análisis de [los DESCA] entre con especial fuerza para dirigir a las autoridades nacionales hacia una toma en serio de tales derechos, como un camino decisivo para el fortalecimiento democrático" (Parra Vera, 2018, p. 234), lo que conduce a la obligación de su observancia por parte de los tribunales nacionales, habida cuenta de que "[...] dichos estándares interpretativos [...] involucran no solo a las disposiciones normativas de las que el Estado sea parte, sino también a su interpretación" (Martínez Ramírez, 2018, p. 385).

Por ello, la exigibilidad de los DESCA a nivel interno deviene en el empleo de los procesos constitucionales (mecanismos procesales determinados e idóneos para garantizar estos derechos fundamentales), a fin de lograr su cumplimiento y satisfacción, lo que se desarrollará a continuación.

\section{Los DESCA reconocidos y protegidos en nuestro ordenamiento jurídico a partir de la jurisprudencia del Tribunal Constitucional}

Así, para culminar este apartado, listamos un conjunto de derechos que forman parte de los DESCA reconocidos y amparados constitucionalmente, para los cuales se ha logrado una protección a través de los procesos constitucionales ${ }^{24}$, tal como ha procedido el TC para tutelar los derechos fundamentales, permitiendo el cumplimiento de la particularidad de justiciabilidad previamente señalada.

Es importante indicar que esta no es una lista cerrada y única de los DESCA acerca de los cuales el TC ha tenido la oportunidad de pronunciarse y desarrollar sus contenidos constitucionales a partir de su jurisprudencia. Más bien, este es un catálogo de derechos que hemos elegido con el objetivo de plasmar lo expuesto hasta ahora, dada su relación con las características explicadas en el apartado anterior.

\section{Derecho a la salud}

El derecho a la salud, reconocido en el artículo 7 de la Constitución Política, que determina: "Todos tienen derecho a la protección de su salud, la del medio familiar y la de la comunidad [...], así como el deber de contribuir a su promoción y defensa. [...]", ha sido materia de diversos pronunciamientos del TC, los cuales han permitido colmar de contenido el citado derecho (STC. Exp. N. ${ }^{\circ}$ 2016-2004-AA/TC, 2004, fundamentos jurídicos 25-32; STC. Exp. N. ${ }^{\circ}$ 6534-2006-PA/TC, 2007, fundamentos jurídicos 7-9).

24 Cabe precisar que muchos de estos planteamientos han sido abordados y desarrollados en su momento en Roel Alva (2017). 
Ahora bien, con relación a su concreción en una política pública de Estado, tenemos lo relativo al derecho al aseguramiento universal en salud, como parte integrante del derecho a la salud, el cual tuvo un trascendente pronunciamiento por parte del TC.

Efectivamente, este tribunal lo sustentó en el carácter no regresivo de los DESCA, declarando lo siguiente:

Esta ampliación de la cobertura de las necesidades de salud tiene su fundamento en el principio de progresividad de los derechos económicos, sociales y culturales. Tal principio, si bien no garantiza que la plena efectividad de estos derechos pueda ser alcanzada inmediatamente, no por ello se encuentra privado de valor jurídico. La primera consecuencia de su establecimiento es que las medidas que deba adoptar el Estado con referencia a la plena efectividad de los derechos económicos, sociales y culturales, para empezar, no pueden ser "regresivas", esto es, que generen un estado de cosas o una situación que sea más perjudicial a la que se encuentre efectivamente establecida [cursivas añadidas]. En el ámbito de la salud, dicho principio se encuentra previsto en el artículo 4 de la Ley N. ${ }^{\circ} 29344$, al establecer el denominado principio de irreversibilidad, según el cual las prestaciones de salud a las que se tenía acceso antes de que se inicie el proceso de aseguramiento universal en salud, y durante el mismo, no pueden sufrir ningún menoscabo como consecuencia de algún proceso posterior. (STC. Exp. N. ${ }^{\circ}$ 0033-2010-AI/TC, 2012. fundamento jurídico 21)

En concordancia con lo establecido por el TC, la Ley Marco del Aseguramiento Universal en Salud, Ley N..$^{\circ}$ 29344, prescribe en su artículo 20 que "[e]l Estado debe incrementar progresivamente, cada año, de manera obligatoria los fondos destinados al financiamiento del régimen subsidiado y semicontributivo", es decir que el financiamiento de la atención en salud para las personas en situación de pobreza ha sido institucionalizado por dicha norma y, por lo tanto, tiene el carácter de irreversible (STC. Exp. N. ${ }^{\circ}$ 0033-2010-Al/TC, 2012, fundamento jurídico 41)

\section{Derecho a la educación}

En cuanto al derecho a la educación, su contenido constitucionalmente protegido se encuentra en una diversidad de disposiciones de la Constitución Política, conforme lo ha sostenido el TC:

De esta forma su contenido constitucionalmente protegido está determinado por el acceso a una educación adecuada (artículo 16), la libertad de enseñanza (artículo 13), la libre elección del centro docente (artículo 13), el respeto a la libertad de conciencia de los estudiantes (artículo 14), el respeto a la identidad de los educandos, así como a un buen trato psicológico y físico (artículo 15), la libertad de cátedra (artículo 18), y la libertad de creación de centros docentes y universidades (artículos 17 y 18). (STC. Exp. N. ${ }^{\circ} 0091-2005-P A / T C, ~ 2005$, fundamento jurídico 6) 
Asimismo, sobre este derecho podemos advertir que es tanto un derecho como un servicio público. Sobre dicha doble naturaleza, el TC correspondió su dimensión de servicio público con el principio de progresividad previamente desarrollado, llegando a señalar lo siguiente:

[E]l Estado tiene la obligación de garantizar la continuidad de los servicios educativos, así como de aumentar progresivamente la cobertura y calidad de los mismos [cursivas añadidas], debiendo tener siempre como premisa básica, como ya se ha mencionado, que tanto el derecho a la educación como todos los derechos fundamentales (e incluso las disposiciones constitucionales que regulan la actuación de los órganos constitucionales) tienen como fundamento el principio de la dignidad humana. (STC. Exp. N. ${ }^{\circ}$ 4232-2004-AA/TC, 2005, fundamento jurídico 12)

Según lo anterior, si bien la plena realización del derecho es una obligación de carácter progresivo, debe imponerse una obligación mínima de asegurar el cumplimiento de la satisfacción de por lo menos los niveles esenciales de cada uno de estos derechos (Comité de Derechos Económicos, Sociales y Culturales [CESCR], 1990), los cuales serán exigibles directamente ante la jurisdicción constitucional (Alvites, 2008, p. 696).

\section{Derecho a la pensión y a la seguridad social}

El derecho a la pensión y a la seguridad social se encuentra regulado constitucionalmente en los artículos $10^{25}$ y $11^{26}$ de nuestra Constitución Política de 1993. A partir de la lectura conjunta de estas dos disposiciones constitucionales, el Supremo Intérprete de nuestra Constitución determinó la naturaleza social-patrimonial de este derecho fundamental, y determinó que el Estado peruano tiene la obligación de procurar una prestación mínima económica que asegure la subsistencia de los ciudadanos que reúnen los requisitos para ser considerados como pensionistas ${ }^{27}$.

25 Constitución Política: "Artículo 10.- El Estado reconoce el derecho universal y progresivo de toda persona a la seguridad social, para su protección frente a las contingencias que precise la ley y para la elevación de su calidad de vida".

26 Constitución Política: “Artículo 11.- El Estado garantiza el libre acceso a prestaciones de salud y a pensiones, a través de entidades públicas, privadas o mixtas. Supervisa asimismo su eficaz funcionamiento. La ley establece la entidad del Gobierno Nacional que administra los regímenes de pensiones a cargo del Estado".

27 Al respecto, el Tribunal Constitucional ha establecido: "Mediante el derecho fundamental a la pensión, la Constitución de 1993 garantiza el acceso de las personas a una pensión que les permita llevar una vida en condiciones de dignidad. Este derecho fundamental también comporta el derecho de las personas a no ser privadas de modo arbitrario e injustificado de la pensión; de ahí que corresponda garantizar, frente a la privación arbitraria e irrazonable, el goce de este derecho, sin perjuicio de reconocer el disfrute de una pensión mínima vital como materialización concreta del clásico contenido esencial del derecho a la pensión" (STC. Exps. N. ${ }^{\circ} 0050-2004-A I / T C,{ }^{\circ}{ }^{\circ} 0051-$ 2004-AI/TC, N. ${ }^{\circ} 0004-2005-\mathrm{PI} / T C, \mathrm{~N}^{\circ}$ 0007-2005-PI/TC y N. ${ }^{\circ}$ 0009-2005-PI/TC, acumulados, 2005, fundamento jurídico 107). 
En cuanto al derecho a la pensión, el TC señala que

[...] tiene la naturaleza de derecho social - de contenido económico-. Surgido históricamente en el tránsito del Estado liberal al Estado social de derecho, impone a los poderes públicos la obligación de proporcionar las prestaciones adecuadas a las personas en función de criterios y requisitos determinados legislativamente, para subvenir sus necesidades vitales y satisfacer los estándares de la "procura existencial" [cursivas añadidas]. De esta forma se supera la visión tradicional que suponía distintos niveles de protección entre los derechos civiles, políticos, sociales y económicos, atendiendo al principio de indivisibilidad de los derechos fundamentales y a que cada uno formaba un complejo de obligaciones de respeto y protección -negativas-y de garantía y promoción - positivas- por parte del Estado". (STC. Exp. N. ${ }^{\circ}$ 1417-2005-AA/TC, 2005, fundamento jurídico 32)

Como se puede apreciar, la indivisibilidad de los DESCA desarrollada por el TC implica que deben ser entendidos de modo integral, "[...] sin jerarquía entre sí y exigibles en todos los casos ante aquellas autoridades que resulten competentes para ello" (Corte IDH, 2015, párr. 172). En el caso concreto, el TC afirmó que "[...] tal es el caso de los derechos a prestaciones de salud y a la pensión [...] y que deben ser otorgados en el marco del sistema de seguridad social" (STC. Exp. N. ${ }^{\circ}$ 1417-2005-AA/TC, 2005, fundamento jurídico 31).

Derecho a un medio ambiente equilibrado y adecuado para el desarrollo de la persona humana

Consideramos que resultan de suma importancia los pronunciamientos del TC en relación con el derecho fundamental a un medio ambiente equilibrado y adecuado para el desarrollo de la persona humana. En ellos ha desarrollado su contenido constitucionalmente protegido a partir de lo establecido en el numeral 22 del artículo 2 de la Constitución Política, en el cual se dispone que toda persona tiene derecho "[...] a gozar de un ambiente equilibrado y adecuado al desarrollo de su vida".

Así, el TC concluyó que el contenido del citado derecho se encuentra determinado:

[...] por los siguientes elementos; a saber: 1) el derecho a gozar de ese medio ambiente y 2) el derecho a que ese medio ambiente se preserve [cursivas añadidas]. [...], en su primera manifestación, esto es, el derecho a gozar de un medio ambiente equilibrado y adecuado, comporta la facultad de las personas de poder disfrutar de un medio ambiente en el que sus elementos se desarrollan e interrelacionan de manera natural y armónica; y, en el caso de que el hombre intervenga, no debe suponer una alteración sustantiva de la interrelación que existe entre los elementos del medio ambiente. Esto supone, por tanto, el disfrute no de cualquier entorno, sino únicamente del adecuado para el desarrollo de la persona y de su dignidad (artículo 1 de la Constitución) [cursivas añadidas]. De lo contrario, su goce se vería frustrado y el derecho quedaría, así, carente de contenido. Y, con relación al segundo acápite, dice la sentencia que el derecho en análisis se concretiza en el derecho a que el 
medio ambiente se preserve. El derecho a la preservación de un medio ambiente sano y equilibrado entraña obligaciones ineludibles, para los poderes públicos, de mantener los bienes ambientales en las condiciones adecuadas para su disfrute. A juicio de este Tribunal, tal obligación alcanza también a los particulares, y con mayor razón a aquellos cuyas actividades económicas inciden, directa o indirectamente, en el medio ambiente. (STC. Exp. N. ${ }^{\circ} 3510-2003-A A / T C, 2005$, fundamento jurídico 2.d)

Por otro lado, el contenido constitucional protegido de este derecho ha sido perfeccionado y reconocido en reiterada y coherente jurisprudencia del TC ${ }^{28}$, la cual ha establecido deberes tanto para la administración pública como para los privados. Así, ha determinado los principios que de forma obligatoria deben ser utilizados y aplicados por el Estado peruano para fiscalizar las actividades económicas y su impacto en el medio ambiente, con especial relevancia para las actividades de explotación de recursos naturales ${ }^{29}$.

\section{Derecho a la alimentación}

Por último, expondremos sobre el derecho constitucional a la alimentación, el cual forma parte de nuestro ordenamiento jurídico a partir de la jurisprudencia del TC, que ha determinado:

Este Tribunal Constitucional considera que el derecho a una alimentación adecuada es un derecho que no solamente tiene reconocimiento a nivel de los tratados internacionales sobre derechos humanos, sino que, además, tiene reconocimiento y vigencia en el ordenamiento jurídico peruano en tanto los tratados que los reconocen han sido aprobados e incorporados como derecho interno. [...] El derecho a la alimentación es, como se desprende de los anteriores considerandos, un

28 Véase, entre otras decisiones emitidas por el Tribunal Constitucional en esta materia, las siguientes: STC. Exp. N. ${ }^{\circ} 3343-2007-A A / T C ;$ STC. Exp. N. ${ }^{\circ} 0018-2001-A I / T C ; ~ S T C . ~ E x p . ~ N .{ }^{\circ}$ 0964-2002-AA/TC;

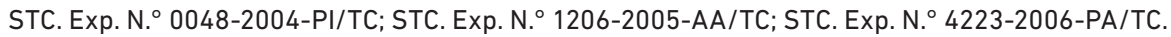

29 En relación con estos principios, el Tribunal Constitucional ha detallado: "En cuanto al vínculo existente entre las actividades económicas y el derecho a un ambiente equilibrado y adecuado al desarrollo de la vida, la jurisprudencia de este Colegiado ha considerado que este se materializa en función de los siguientes principios: (1) el principio de desarrollo sostenible o sustentable [cursivas añadidas] (que merecerá luego un análisis), (2) el principio de conservación [cursivas añadidas], en cuyo mérito se busca mantener en estado óptimo los bienes ambientales; (3) el principio de prevención [cursivas añadidas], que supone resguardar los bienes ambientales de cualquier peligro que pueda afectar a su existencia; (4) el principio de restauración [cursivas añadidas], referido al saneamiento y recuperación de los bienes ambientales deteriorados, (4) el principio de mejora [cursivas añadidas], en cuya virtud se busca maximizar los beneficios de los bienes ambientales en pro del disfrute humano, (5) el principio precautorio [cursivas añadidas], que comporta adoptar medidas de cautela y reserva cuando exista incertidumbre científica e indicios de amenaza sobre la real dimensión de los efectos de las actividades humanas sobre el ambiente, y (6) el principio de compensación [cursivas añadidas], que implica la creación de mecanismos de reparación por la explotación de los recursos no renovables [...]" (STC. Exp. N. ${ }^{\circ}$ 4223-2006-PA/TC, 2007, fundamento jurídico 23). 
derecho existente en el ordenamiento jurídico peruano, siendo necesario que este Tribunal Constitucional proceda a identificar su estructura como derecho social, así como delinear el contenido constitucionalmente protegido de este. (STC. Exp. N. ${ }^{\circ} 1470-2016-\mathrm{PHC} / \mathrm{TC}, 2019$, fundamentos jurídicos 12 y 15)

Asimismo, el TC señaló que este derecho social faculta a su titular a obtener una prestación positiva por parte del Estado ${ }^{30}$ y estableció que, para concretarla, esta prestación tiene que ser progresiva en tanto se desarrolla en función de tres umbrales de satisfacción ${ }^{31}$ :

1. Primer umbral. El derecho a una alimentación de subsistencia exige que se provea al ciudadano, que se encuentre en una situación de vulnerabilidad, de alimentos que le permitan encontrarse libre de padecer hambre y mantener sus funciones corporales ${ }^{32}$.

2. Segundo umbral. Para cumplir con el segundo umbral se exige que se desarrollen y concreten de forma progresiva las políticas públicas en materia alimentaria ${ }^{33}$.

30 En relación con este extremo, el Tribunal Constitucional “[...] entiende que el derecho a la alimentación es una posición jurídica de derecho subjetivo que faculta a su titular a obtener una prestación positiva por parte del Estado, a fin de que este le provea o le haga accesibles los medios suficientes y adecuados que satisfagan sus requerimientos alimenticios de manera sostenible, cuando su titular se encuentre en una situación de vulnerabilidad que le impida satisfacerlos por sí mismo. El Estado está obligado de satisfacer una alimentación de subsistencia que permita al titular del derecho verse libre de padecer hambre (sensación incómoda o dolorosa causada por la falta de comida) y mantener su funcionalidad corporal, siendo progresivo el desarrollo y complementación de dicho mínimo" (STC. Exp. N. ${ }^{\circ}$ 1470-2016-PHC/TC, 2019, fundamento jurídico 39).

31 Sobre la progresividad en el cumplimiento de este derecho, el Tribunal Constitucional ha declarado que "[...] la concretización del derecho social fundamental a la alimentación es progresiva en tanto se desarrolla en función de umbrales de satisfacción, a la vez reconoce una obligación incondicional mínima del Estado en asegurar la provisión y acceso a alimentos que evitan padecer hambre a sus titulares y garantizan la funcionalidad corporal de los mismos" (STC. Exp. N. ${ }^{1470-2016-}$ PHC/TC, 2019, fundamento jurídico 41).

32 Respecto del primer umbral de satisfacción del derecho a la alimentación, el Tribunal Constitucional ha declarado: "El primer umbral de realización o cumplimiento del derecho social fundamental a la alimentación lo constituye el derecho a una alimentación de subsistencia. Dicho derecho viene a ser una obligación de cumplimiento incondicionado para el Estado, ya que representa el grado mínimo de provisión alimentaria que un ciudadano, que se encuentre en una situación de vulnerabilidad que le impida poder brindársela por sí mismo, debe tener garantizada para verse libre de padecer hambre y mantener sus funciones corporales. Sin tal nivel mínimo de provisión, los ciudadanos no podrían tener una existencia digna y no estarían en posibilidad de gozar sus demás derechos fundamentales. [...] La alimentación de subsistencia no solo implica poner a disposición de las personas en estado de vulnerabilidad los alimentos que contengan el número de calorías, proteínas y demás nutrientes que les permitan mantener su funcionalidad corporal, sino que también implica hacer accesibles dichos alimentos a quienes los necesiten, garantizando la permanencia y sostenibilidad de las vías que así lo permitan" (STC. Exp. N. ${ }^{\circ}$ 1470-2016-PHC/TC, 2019, fundamento jurídico 40).

33 Respecto del segundo umbral de satisfacción del derecho a la alimentación, el Tribunal Constitucional ha declarado: “El segundo umbral de realización o cumplimiento del derecho a la alimentación gira en torno a las políticas programáticas que complementan a la alimentación de subsistencia garantizada en el primer umbral. Es a este nivel que el desarrollo y concretización 
3. Tercer umbral. Este último umbral exige que el Estado realice acciones orientadas a satisfacer las necesidades alimentarias de los ciudadanos, los cuales pueden ser intereses o propósitos especiales de forma individual o colectiva ${ }^{34}$.

A partir de estos umbrales podemos reconocer la relevancia de este derecho, el cual tiene su sustento en los niveles de cumplimiento progresivo por parte del Estado peruano. Este aspecto es relevante para la comprensión de los DESCA, puesto que cabe recordar que "[...] la obligación estatal de proteger tales derechos implica la adopción de medidas que [los] protejan, aseguren y promuevan" (Martínez Ramírez, 2018, p. 384), y que, además, debe considerarse que dicho derecho, conforme destaca el propio TC, "[...] es inseparable de la dignidad humana y es una precondición necesaria para el disfrute de otros derechos humanos" (STC. Exp. N. ${ }^{\circ}$ 1470-2016-PHC/TC, 2019, fundamento jurídico 36).

\section{LOS PROCESOS CONSTITUCIONALES COMO MEDIOS IDÓNEOS PARA LA EFECTIVIDAD DE LOS DERECHOS PROGRAMÁTICOS}

Conforme señalamos en la introducción de este artículo, nuestro planteamiento es sustentar la relevancia de los procesos constitucionales en la protección de los derechos programáticos. Así, los derechos constitucionales previamente mencionados en el apartado anterior y que pertenecen al grupo de los DESCA fueron, en su momento, protegidos a través de los procesos constitucionales, los cuales, conforme a nuestro ordenamiento constitucional, son los medios procesales elegidos por nuestro constituyente para garantizar los derechos reconocidos en la Constitución Política.

de las políticas públicas en materia alimentaria son aplicadas de manera progresiva por parte del Estado. Dichas políticas deben estar orientadas a lograr seguridad alimentaria en la sociedad, es decir, asegurar el acceso permanente a medios de alimentación suficientes que permitan a los ciudadanos llevar una vida activa, saludable y sin necesidad de recurrir a los medios de alimentación de subsistencia garantizados en el primer umbral para poder satisfacer sus necesidades alimentarias. La obligación del Estado en este segundo umbral, si bien es cierto que es progresiva y sujeta a cuestiones presupuestales, no por ello implica que se encuentre enteramente a su libre discrecionalidad. En efecto, la obligación en este segundo umbral radica en implementar políticas públicas en materia alimentaria de manera progresiva, por lo que incumplir con tal implementación equivale a un incumplimiento de la obligación" (STC. Exp. N. ${ }^{\circ}$ 1470-2016-PHC/TC, 2019, fundamento jurídico 40).

34 Respecto del tercer umbral de satisfacción del derecho a la alimentación, el Tribunal Constitucional ha declarado: “El tercer umbral de realización o cumplimiento del derecho a la alimentación está conformado por las acciones estatales orientadas a satisfacer necesidades alimentarias de los ciudadanos basados en los especiales intereses o propósitos que estos tengan en su vida individual o colectiva. En este umbral, el grado de discrecionalidad con el cual el Estado puede operar es mayor que a nivel del segundo umbral, dado que su acción ahora está orientada a satisfacer intereses alimentarios específicos de determinados individuos o grupo de individuos y no en función de alcanzar el aseguramiento alimentario de toda la comunidad en su conjunto. En ese sentido, la satisfacción de este umbral será posible una vez se haya logrado satisfacer el primero y cumplido con desarrollar políticas alimentarias eficaces a nivel del segundo umbral" (STC. Exp. N. ${ }^{\circ} 1470-$ 2016-PHC/TC, 2019, fundamento jurídico 40). 
De igual forma, siguiendo lo desarrollado en la presente investigación, consideramos que una de las particularidades de los DESCA es que requieren de justiciabilidad directa, de acuerdo con la reciente jurisprudencia de la Corte IDH en el caso Lagos del Campo vs. Perú, así como también han de tener medios de protección para tal efecto en sede interna. Así pues, presentamos a los procesos constitucionales de amparo y cumplimiento como los medios procesales idóneos para garantizar la efectividad de los DESCA, los cuales, según la precitada jurisprudencia del TC, han cumplido este objetivo.

\section{Los procesos constitucionales como medios idóneos para garantizar los DESCA en nuestro ordenamiento jurídico}

Antes de desarrollar las nociones relacionadas con los procesos constitucionales de amparo y cumplimiento, los cuales son los medios procesales idóneos para garantizar la efectividad de los DESCA, debemos advertir la relevancia que ha tenido el TC en este aspecto, puesto que este último se ha convertido en un garante de los DESCA ${ }^{35}$. Al respecto, el profesor César Landa (2007), en relación con el desarrollo jurisprudencial en esta materia por parte del TC, ha declarado que

[...] ha sido en el ámbito de la justicia constitucional donde los derechos sociales han obtenido no solo protección ya sea frente a la administración estatal y al legislador, sino también un desarrollo importante a partir de la jurisprudencia del Tribunal Constitucional, la misma que ha precisado su progresividad, exigibilidad, así como sus límites. Con lo cual se van asentando, en nuestro ordenamiento constitucional, las bases para superar aquella concepción positivista y formal que ve en los derechos sociales meras declaraciones programáticas, lo cual no es una tarea fácil, puesto que esta forma de concebirlos se deriva, en último término, de una debilidad política que es también fruto de una debilidad teórica [cursivas añadidas]. (p. 365)

35 Nuestro Tribunal Constitucional se ha pronunciado en diferentes oportunidades respecto a los derechos económicos, sociales, culturales y ambientales (DESCA). En este sentido, ha desarrollado un catálogo de estos derechos, así como su contenido constitucionalmente protegido. De esta forma, presentamos un breve índice de estos derechos conjuntamente con sus respectivos pronunciamientos que desarrollan su contenido constitucionalmente protegido, que, a nuestra consideración, son los más relevantes. Así, tenemos el derecho a la salud (STC. Exp. N. ${ }^{\circ}$ 2016-2004-PA/TC; STC. Exp. N. ${ }^{\circ}$ 0032- 2010-PI/TC), el derecho a la pensión y a la seguridad social (STC. Exps. N. ${ }^{\circ} 0050-2004-A I / T C$,

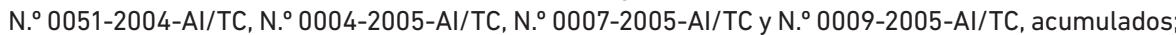
STC. Exp. N. ${ }^{\circ}$ 5658-2006-PA/TC), el derecho al trabajo (STC. Exp. N. ${ }^{\circ}$ 0206-2005-AA/TC; STC. Exp. N. ${ }^{\circ}$ 0976-2001-AA/TC; STC. Exp. N. ${ }^{\circ}$ 1124-2001-AA/TC), el derecho a la educación (STC. Exp. N. ${ }^{\circ} 0014-$ 2014-PI/TC; STC. Exp. N. ${ }^{\circ} 0016-2014-\mathrm{PI} / \mathrm{TC}$; STC. Exps. N. ${ }^{\circ} 0019-2014-\mathrm{PI} / \mathrm{TC}$ y N. ${ }^{\circ}$ 0007-2015-PI/TC, acumulados; STC. Exp. N. ${ }^{\circ} 0853-2015-\mathrm{PA} / \mathrm{TC}$ ), el derecho a la identidad cultural (STC. Exps. N. ${ }^{\circ} 0020-$ 2005-PI/TC y N. ${ }^{\circ}$ 0021-2005-PI/TC, acumulados; STC. Exp. N. ${ }^{\circ}$ 0006-2008-PI/TC), el derecho al medio ambiente sano y equilibrado (STC. Exp. N. ${ }^{\circ}$ 0018-2001-AI/TC; STC. Exp. N. ${ }^{\circ}$ 0964-2002-AA/TC), como figura en Roel Alva (2018, pp. 675-676, nota a pie de página 105). 
En este mismo sentido, el propio TC ha llegado a sustentar lo siguiente respecto al proceder del Estado peruano frente a los DESCA:

Es importante que la ejecución presupuestal en las políticas sociales deje de ser vista como un mero gasto y se piense, más bien, en los términos de una inversión social en aras del cumplimiento de un fin comunitario. Únicamente cuando todos los ciudadanos gocen de garantías mínimas de bienestar, podrán realizar satisfactoriamente sus planes de vida $y$, por consiguiente, brindar un mejor aporte a la sociedad en su conjunto, lográndose, de este modo, un mayor desarrollo como país. (STC. N. ${ }^{\circ}$ 2016-2004-AA/TC, 2004, fundamento jurídico 43)

Por otro lado, es preciso señalar que, si bien la mayoría de los pronunciamientos del TC han tenido un efecto positivo en la protección de estos derechos, también debemos afirmar que en otras oportunidades este mismo tribunal ha preferido optar por restringir la protección constitucional de estos, lo que constituye una modificación retroactiva significativa en relación con el enfoque jurisdiccional inicial que había brindado este órgano constitucional ${ }^{36}$.

\section{El proceso de amparo como medio procesal para lograr la efectividad de los derechos programáticos}

En este acápite presentamos el proceso constitucional de amparo, el cual, conforme a lo previsto en la Constitución Política y el Código Procesal Constitucional, es el medio procesal encargado de proteger los derechos constitucionales que no son tutelados por los procesos constitucionales de habeas corpus y habeas data. Siendo esta su finalidad, se le ha encargado la protección, por excelencia, de los DESCA. Así, el TC concluyó:

Lo expuesto significa que en determinadas circunstancias los DESC no pueden ser objeto de una pretensión susceptible de estimación al interior del proceso de amparo (vg. la exigencia judicial al Estado de un puesto de trabajo o una prestación de vivienda). Ello, sin embargo, no puede ser considerado como una regla absoluta. (STC. Exp. N. ${ }^{\circ}$ 1417-2005-PA/TC, 2005, fundamento jurídico 15)

Un ejemplo relevante al respecto es que el TC habilitó la procedencia del proceso constitucional de amparo para garantizar el derecho a la pensión y a la seguridad social -ya desarrollado en este artículo- cuando este se encuentre afectado por los entes

36 Al respecto, podemos decir que "[e]n relación con los derechos económicos, sociales, culturales y ambientales (DESCA), el Tribunal Constitucional peruano ha tenido un rol muy activo, desarrollando sus contenidos y ampliando sus alcances de protección por parte del Estado. La mayoría de estos pronunciamientos han tenido un efecto positivo en la protección de estos derechos, los cuales, gracias a la interpretación de este tribunal, se han ampliado y enriquecido en su contenido constitucionalmente protegido, alcances, límites y demás aspectos; sin embargo, no es menos cierto que en otras oportunidades el Tribunal Constitucional ha optado por limitar el acceso a la jurisdicción constitucional para la protección de estos derechos, siendo una modificación retroactiva importante con relación a la posición jurisdiccional inicial de este órgano constitucional” (Roel Alva, 2018, p. 675). 
administradores de fondos de pensiones públicos y privados. Ciertamente, emitió el precedente constitucional vinculante recaído en el Expediente N. ${ }^{\circ}$ 1417-2005-AA/TC, en el cual establece textualmente que

[...] este Tribunal advierte que los criterios jurídicos contenidos en el Fundamento 37 supra para determinar la procedencia de demandas de amparo en materia pensionaria, a partir de la determinación del contenido esencial del derecho fundamental a la pensión [cursivas añadidas], reconocido en el artículo 11 de la Constitución, constituyen precedente vinculante, de conformidad con lo dispuesto en el artículo VII del Título Preliminar del C. P. Const. (STC. Exp. N. ${ }^{\circ} 1417-2005-A A / T C, 2005$, fundamento jurídico 47)

En este apartado queremos destacar que recién con la entrada en vigor del Código Procesal Constitucional se determinó en nuestro ordenamiento jurídico que el proceso constitucional de amparo era el medio idóneo para garantizar los DESCA ${ }^{37}$. Sin embargo, previamente a la emisión de dicho cuerpo procesal, la procedencia del proceso de amparo en esta ocasión fue gracias al TC, como en el precitado caso.

\section{El proceso de cumplimiento como medio procesal para lograr la efectividad de los derechos programáticos}

El proceso constitucional de cumplimiento, conforme a su regulación en la Constitución Política y el Código Procesal Constitucional, “[...] esencialmente busca asegurar la eficacia de las normas legales y los actos administrativos, convirtiendo el cumplimiento de las normas legales y actos administrativos por parte de la autoridad en un derecho fundamental de los ciudadanos" (Landa, 1999, p. 30). En otras palabras, las leyes o actos administrativos constituyen la expresión de la soberanía popular o de la democracia como principio constitucional, por lo que su incumplimiento, "cuando afecta concretamente a una persona, se manifiesta también como el derecho fundamental al cumplimiento de las normas legales y de los actos administrativos" (León Vásquez, 2009, p. 193).

En tal sentido, el TC, a partir de la interpretación de diferentes disposiciones constitucionales, concluyó:

Conforme a los artículos 3, 43 y 45 de la Constitución, el Tribunal Constitucional reconoce la configuración del derecho constitucional a asegurar y exigir la eficacia de las normas legales y de los actos administrativos. Por tanto, cuando una autoridad o funcionario es renuente a acatar una norma legal o un acto administrativo que incide en los derechos de las personas o, incluso, cuando se trate de los casos a que se refiere el artículo 65 del Código Procesal Constitucional (relativos a la defensa de los derechos con intereses difusos o colectivos en el proceso de cumplimiento), surge el derecho de defender la eficacia de las normas legales y

37 Véase el artículo 37 del Código Procesal Constitucional, Ley N.$^{\circ} 28237$. 
actos administrativos a través del proceso constitucional de cumplimiento. (STC. Exp. N. ${ }^{\circ}$ 00168-2005-AC/TC, 2005, fundamento jurídico 9)

De acuerdo con lo expuesto, si bien la naturaleza jurídica del proceso constitucional de cumplimiento se encuentra directamente relacionada con la protección del derecho a defender la eficacia de normas legales y actos administrativos, constituyendo así "[...] un derecho fundamental de los ciudadanos" (Landa, 1999, p. 30); también es cierto que el TC, en su desarrollo jurisprudencial, ha establecido que dicho proceso puede proteger de modo indirecto los DESCA.

En este caso, el derecho que específicamente se garantizó a través del proceso de cumplimiento fue el derecho a la salud de un grupo de pobladores contaminados por plomo (esta situación se conoce como el caso La Oroya), indicando que

[e]n cuanto a la protección "indirecta" del derecho a la salud mediante el proceso de cumplimiento, cabe destacar que procederá siempre y cuando exista un mandato claro, concreto y vigente contenido en una norma legal o en un acto administrativo, mandato que precisamente se deberá encontrar en una relación indisoluble con la protección del referido derecho fundamental. (STC. Exp. N. ${ }^{\circ} 2002-2006-A C / T C$, 2006, fundamento jurídico 18)

Es decir que, si bien en el referido proceso se denunciaba el incumplimiento del mandato establecido en la Ley General de Salud, Ley N. ${ }^{\circ} 26842$, " “...] el mismo que, a su vez, tiene como finalidad la protección del derecho a un medio ambiente equilibrado y adecuado al desarrollo de la vida", así como el derecho a la salud. Por eso, el TC estableció que dicha inacción del Estado vulneraba los referidos derechos de la población de esa zona y que el proceso de cumplimiento era el remedio procesal para el cese de dicha situación (STC. Exp. N. ${ }^{\circ}$ 2002-2006-AC/TC, 2006, fundamentos jurídicos 2, 18 y 27).

\section{CONCLUSIONES}

Como indicamos desde el principio del presente artículo, nuestro objetivo es sustentar la relevancia de los procesos constitucionales en la protección de los derechos económicos, sociales, culturales y ambientales (DESCA). Para alcanzar dicho propósito hemos sostenido que estos procesos tienen como finalidad garantizar la supremacía de la Constitución Política, en cuanto norma suprema dentro de nuestro ordenamiento jurídico, así como proteger a los derechos que poseen reconocimiento constitucional, frente a cualquier amenaza y afectación, teniendo una especial relevancia estos últimos, puesto que protegen al ciudadano frente a cualquier arbitrariedad de los entes estatales y de los particulares que limite o afecte sus derechos.

Asimismo, hemos expuesto el concepto y las principales particularidades de los DESCA. Uno de los aspectos más relevantes para el objeto de este artículo fue el cambio 
de paradigma a partir de la decisión de la Corte IDH recaída en el caso Lagos del Campo vs. Perú, en el cual se establece la justiciabilidad directa de los DESCA, en lo que respecta al derecho a la libertad de asociación. Asimismo, lo es su subsecuente desarrollo jurisprudencial que incluye el derecho a la salud y la seguridad social. Aún estamos a la expectativa de que este desarrollo comprenda a los demás derechos relacionados.

En el ámbito nacional, hemos acreditado que los derechos a la salud, a la educación, a la pensión y a la seguridad social, a un medio ambiente equilibrado y adecuado para el desarrollo de la persona humana, y a la alimentación, han sido protegidos por el TC mediante los procesos constitucionales. De ahí que afirmemos que los procesos constitucionales encargados de la tutela de los derechos constitucionales -amparo y cumplimiento- son los medios idóneos para garantizar la efectividad de los DESCA en sede nacional, conforme hemos expuesto a través de algunos casos emblemáticos.

Así, los procesos constitucionales han demostrado que son medios procesales capaces de garantizar los derechos reconocidos en nuestra Constitución Política, pero al mismo tiempo se requiere la consonancia con la jurisprudencia de la precitada Corte IDH, a fin de promover una mejor y mayor garantía de dichos derechos.

\section{REFERENCIAS}

Abramovich, V., y Courtis, C. (1997). Hacia la exigibilidad de los derechos económicos, sociales y culturales. Estándares internacionales y criterios de aplicación ante los tribunales locales. Recuperado de http://www.oda-alc.org/documentos /1366995147.pdf

Alvites, E. (2008). Aspectos generales sobre los derechos sociales fundamentales en el Perú. En Ponencias desarrolladas del IX Congreso Nacional de Derecho Constitucional (tomo II, pp. 687-696). Arequipa: ADRUS.

Blume Fortini, E. (2011). Paradigmas del derecho procesal constitucional. Revista Estado Constitucional, 1(4).

Clérico, L., Ronconi, L., y Aldao, M. (2013). Hacia la reconstrucción de las tendencias jurisprudenciales en América Latina y el Caribe en materia de igualdad: sobre la no discriminación, la no dominación y la redistribución y el reconocimiento. Revista Direito GV, 9(1). https://doi.org/10.1590/S1808-24322013000100006

Comisión Interamericana de Derechos Humanos [CIDH]. (2018). Il Informe Anual de la Relatoría Especial sobre Derechos Económicos, Sociales, Culturales y Ambientales (REDESCA). Washington D. C.: Autor. Recuperado de http://www.oas.org/es/cidh/ docs/anual/2018/docs/IA2018REDESCA-es.pdf 
Comité de Derechos Económicos, Sociales y Culturales [CESCR]. (14 de diciembre de 1990). Observación general N. ${ }^{\circ}$ 3. Índole de las obligaciones de los Estados Partes (párrafo 1 del artículo 2 del Pacto). Recuperado de https://www.acnur.org/ fileadmin/Documentos/BDL/2001/1452.pdf

Corte Interamericana de Derechos Humanos [Corte IDH]. (1 de julio del 2009). Sentencia en el caso Acevedo Buendía y otros ("Cesantes y Jubilados de la Contraloría") vs. Perú. Recuperado de https://www.corteidh.or.cr/docs/casos/articulos/ seriec_198_esp.pdf

Corte Interamericana de Derechos Humanos [Corte IDH]. (1 de septiembre del 2015). Sentencia en el caso Gonzales Lluy y otros vs. Ecuador. Recuperado de https:// www.corteidh.or.cr/docs/casos/articulos/seriec_298_esp.pdf

Corte Interamericana de Derechos Humanos [Corte IDH]. (31 de agosto del 2017). Sentencia en el caso Lagos del Campo vs. Perú. Recuperado de https://www. corteidh.or.cr/corteidh/docs/casos/articulos/seriec_340_esp.pdf

Corte Interamericana de Derechos Humanos [Corte IDH]. (23 de agosto del 2018). Sentencia en el caso Cuscul Pivaral y otros vs. Guatemala. Recuperado de https://www.corteidh.or.cr/docs/casos/articulos/seriec_359_esp.pdf

De Otto, I. (1998). Derecho constitucional. Sistema de fuentes. Barcelona: Ariel.

Ferrer McGregor, E., Morales Antoniazzi, M., y Flores Pantoja, R. (Coords.). (2018). Inclusión, lus Commune y justiciabilidad de los DESCA en la jurisprudencia interamericana. El caso Lagos del Campo y los nuevos desafíos. Ciudad de México: Instituto de Estudios Constitucionales del Estado de Querétaro. Recuperado de https:// biblio.juridicas.unam. $\mathrm{mx} / \mathrm{bjv} /$ detalle-libro/4817-inclusion-ius-commune-yjusticiabilidad-de-los-desca-en-la-jurisprudencia-interamericana-el-casolagos-del-campo-y-los-nuevos-desafios-coleccion-constitucion-y-derechos

Landa, C. (1999). Los procesos constitucionales en la Constitución Peruana de 1993. Ius et Veritas, 9(18), 8-36. Recuperado de http://revistas.pucp.edu.pe/index.php/ iusetveritas/article/view/15818/16250

Landa, C. (2007). Tribunal Constitucional y Estado democrático (3. ${ }^{\text {a }}$ ed.). Lima: Palestra Editores.

Landa, C. (2009). Autonomía procesal del Tribunal Constitucional: la experiencia del Perú. En Anuario de Derecho Constitucional Latinoamericano 2009 (pp. 277-310). Montevideo: Konrad-Adenauer-Stiftung E. V. Recuperado de https:// www.kas.de/c/document_library/get_file?uuid=4da0e369-ffc1-3b41-c957fe2ed7863cb2\&groupld=252038 
Landa, C. (2011). Derecho procesal constitucional. Cuaderno de trabajo n. ${ }^{\circ} 20$. Lima: Departamento Académico de Derecho de la Pontificia Universidad Católica del Perú. Recuperado de http://repositorio.pucp.edu.pe/index/bitstream/handle/ 123456789/46730/cuaderno\%2020.pdf?sequence=1\&isAllowed=y

Landa, C. (2013). La constitucionalización del derecho peruano. Derecho PUCP, (71), 13-36. doi: https://doi.org/10.18800/derechopucp.201302.001

León Vásquez, J. (2009). El proceso constitucional de cumplimiento y su incidencia positiva en la protección del Estado democrático de derecho. Foro Jurídico, (09), 188-196. http://revistas.pucp.edu.pe/index.php/forojuridico/article/view/18530

Martínez Ramírez, F. (2018). La influencia de la jurisprudencia de la Corte Interamericana en materia de derechos económicos, sociales y culturales en la interpretación y resolución de casos en México. En E. Ferrer McGregor, M. Morales Antoniazzi y R. Flores Pantoja (Coords.), Inclusión, lus Commune y justiciabilidad de los DESCA en la jurisprudencia interamericana. El caso Lagos del Campo y los nuevos desafíos (pp. 381-402). Ciudad de México: Instituto de Estudios Constitucionales del Estado de Querétaro. Recuperado de https://biblio.juridicas.unam.mx/bjv/ detalle-libro/4817-inclusion-ius-commune-y-justiciabilidad-de-los-desca-enla-jurisprudencia-interamericana-el-caso-lagos-del-campo-y-los-nuevosdesafios-coleccion-constitucion-y-derechos

Méndez, J. E. (2004). Derechos económicos, sociales y culturales: experiencias y posibilidades dentro del sistema interamericano. En Construyendo una agenda para la justiciabilidad de los derechos sociales (pp. 115-143). San José: Centro por la Justicia y el Desarrollo Internacional (CEJIL). Recuperado de https://archivos. juridicas.unam.mx/www/bjv/libros/10/4556/7.pdf

Nash Rojas, C. (2011). Los derechos económicos, sociales y culturales y la justicia constitucional latinoamericana: tendencias jurisprudenciales. Estudios Constitucionales, 9(1), 65-118. Recuperado de https://scielo.conicyt.cl/pdf/ estconst/v9n1/art04.pdf

Parra Vera, Ó. (2018). La justiciabilidad de los derechos económicos, sociales y culturales en el Sistema Interamericano a la luz del artículo 26 de la Convención Americana. El sentido y la promesa del caso Lagos del Campo. En E. Ferrer McGregor, M. Morales Antoniazzi y R. Flores Pantoja (Coords.), Inclusión, lus Commune y justiciabilidad de los DESCA en la jurisprudencia interamericana. El caso Lagos del Campo y los nuevos desafíos (pp. 181-234). Ciudad de México: Instituto de Estudios Constitucionales del Estado de Querétaro. Recuperado de https://biblio.juridicas. unam.mx/bjv/detalle-libro/4817-inclusion-ius-commune-y-justiciabilidad-de- 
los-desca-en-la-jurisprudencia-interamericana-el-caso-lagos-del-campo-ylos-nuevos-desafios-coleccion-constitucion-y-derechos

Resolución recaída en los Expedientes N. ${ }^{\circ}$ 0025-2005-PI/TC y N. ${ }^{\circ}$ 0026-2005-PI/TC. (2005). Tribunal Constitucional del Perú. Recuperado de https://www.tc.gob.pe/ jurisprudencia/2006/00025-2005-Al\%2000026-2005-Al\%20Admisibilidad.html

Resolución recaída en el Expediente N. ${ }^{\circ} 0033-2005-A I / T C . ~(2006)$. Tribunal Constitucional del Perú. Recuperado de https://www.tc.gob.pe/jurisprudencia/2006/000332005-Al\%20Resolucion.html

Roel Alva, L. A. (2017). El Tribunal Constitucional peruano como agente de cambio de la realidad nacional: planteamiento a partir del estudio y análisis de sus sentencias (tesis para obtener el título de máster en Derecho Constitucional). Universidad de Castilla-La Mancha, Toledo, España.

Roel Alva, L. A. (2018). Tribunal Constitucional peruano: una concepción a partir de los aportes de Javier Alva Orlandini a la justicia constitucional peruana. En L. A. Roel Alva (Coord.), Política y derecho constitucional. Homenaje a Javier Alva Orlandini (pp. 637-680). Arequipa: ADRUS.

Roel Alva, L. A., y Huayta Alipio, D. M. (2018). La efectividad de los pronunciamientos del Sistema Interamericano de Protección de Derechos Humanos. En E. Blume Fortini (Coord.), Desafíos del constitucionalismo peruano a los 25 años de la Constitución de 1993. Ponencias del XII Congreso Nacional de Derecho Constitucional (vol. I, pp. 697-727). Trujillo: Fondo Editorial de la Universidad Privada Antenor Orrego.

Rubio, P. (2013). Los derechos económicos, sociales y culturales en el texto de la Constitución y en la jurisprudencia del Tribunal Constitucional. Derecho PUCP, (71), 201-230. https://doi.org/10.18800/derechopucp.201302.008

Sandoval, A. (2001). Los derechos económicos, sociales y culturales. Una revisión del contenido esencial de cada derecho y de las obligaciones del Estado. Ciudad de México: Equipo Pueblo.

Sentencia recaída en los Expedientes N. 0001-2004-Al/TC y N..$^{\circ}$ 0002-2004-Al/TC (acumulados). (2004). Tribunal Constitucional del Perú. Recuperado de https:// www.tc.gob.pe/jurisprudencia/2004/00001-2004-Al\%2000002-2004-Al.pdf

Sentencia recaída en el Expediente N. ${ }^{\circ}$ 2945-2003-AA/TC. (2004). Tribunal Constitucional del Perú. Recuperado de https://tc.gob.pe/jurisprudencia/2004/02945-2003AA.pdf

Sentencia recaída en el Expediente N. ${ }^{\circ}$ 2016-2004-AA/TC. (2004). Tribunal Constitucional del Perú. Recuperado de https://www.tc.gob.pe/jurisprudencia/2005/020162004-AA.pdf 
Sentencia recaída en el Expediente N. ${ }^{\circ}$ 0266-2002-AA/TC. (2005). Tribunal Constitucional del Perú. Recuperado de https://www.tc.gob.pe/jurisprudencia/2005/002662002-AA.html

Sentencia recaída en el Expediente N. ${ }^{\circ}$ 3510-2003-AA/TC. (2005). Tribunal Constitucional del Perú. Recuperado de https://www.tc.gob.pe/jurisprudencia/2005/035102003-AA.html\#: :text=3510\%2D2003\%2DAA\&text=Recurso\%20extraor dinario\%20interpuesto\%20por\%20don,acci\%C3\%B3n\%20de\%20amparo\%20 de\%20autos

Sentencia recaída en el Expediente N. ${ }^{\circ}$ 4232-2004-AA/TC. (2005). Tribunal Constitucional del Perú. Recuperado de https://tc.gob.pe/jurisprudencia/2006/042322004-AA.pdf

Sentencia recaída en los Expedientes N. ${ }^{\circ}$ 0050-2004-AI/TC, N. ${ }^{\circ}$ 0051-2004-AI/TC, N. ${ }^{\circ}$ 0004-2005-PI/TC, N. ${ }^{\circ} 0007-2005-\mathrm{PI} / \mathrm{TC}$ y N. ${ }^{\circ} 0009-2005-\mathrm{PI} / \mathrm{TC}$ (acumulados). (2005). Tribunal Constitucional del Perú. Recuperado de https://tc.gob.pe/jurispru dencia/2005/00050-2004-AI\%2000051-2004-AI\%2000004-2005-AI\%20000072005-AI\%2000009-2005-Al.pdf

Sentencia recaída en el Expediente N. ${ }^{\circ}$ 0005-2005-CC/TC. (2005). Tribunal Constitucional del Perú. Recuperado de https://tc.gob.pe/jurisprudencia/2006/00005-2005 -CC.pdf

Sentencia recaída en los Expedientes N. ${ }^{\circ}$ 0020-2005-PI/TC y N. ${ }^{\circ}$ 0021-2005-PI/TC (acumulados). (2005). Tribunal Constitucional del Perú. Recuperado de https:// www.tc.gob.pe/jurisprudencia/2005/00020-2005-Al\%2000021-2005-Al.pdf

Sentencia recaída en el Expediente N. ${ }^{\circ}$ 0091-2005-PA/TC. (2005). Tribunal Constitucional del Perú. Recuperado de https://tc.gob.pe/jurisprudencia/2006/00091-2005AA.html

Sentencia recaída en el Expediente N. ${ }^{\circ} 00168-2005-A C / T C$. (2005). Tribunal Constitucional del Perú. Recuperado de https://www.tc.gob.pe/jurisprudencia/2005/001682005-AC.html

Sentencia recaída en el Expediente N. ${ }^{\circ}$ 1417-2005-PA/TC. (2005). Tribunal Constitucional del Perú. Recuperado de https://tc.gob.pe/jurisprudencia/2005/01417-2005-AA. html

Sentencia recaída en el Expediente N. ${ }^{\circ} 5854-2005-P A / T C$. (2005). Tribunal Constitucional del Perú. Recuperado de https://www.tc.gob.pe/jurisprudencia/2005/058542005-AA.pdf 
Sentencia recaída en los Expedientes N..$^{\circ}$ 0025-2005-PI/TC y N. ${ }^{\circ}$ 0026-2005-PI/TC (acumulados). (2006). Tribunal Constitucional del Perú. Recuperado de https:// tc.gob.pe/jurisprudencia/2006/00025-2005-Al\%2000026-2005-Al.pdf

Sentencia recaída en el Expediente N. ${ }^{\circ}$ 2002-2006-AC/TC. (2006). Tribunal Constitucional del Perú. Recuperado de https://tc.gob.pe/jurisprudencia/2006/02002-2006-AC. pdf

Sentencia recaída en el Expediente N. ${ }^{\circ}$ 7873-2006-Al/TC. (2006). Tribunal Constitucional del Perú. Recuperado de https://www.tc.gob.pe/jurisprudencia/2007/078732006-AC.pdf

Sentencia recaída en el Expediente N. ${ }^{\circ}$ 4223-2006-PA/TC. (2007). Tribunal Constitucional del Perú. Recuperado de https://tc.gob.pe/jurisprudencia/2007/04223-2006-AA. html\#: :text=El\%20derecho\%20al\%20ambiente\%20equilibrado,vida\%20y\%20 la\%20salud\%20humana.

Sentencia recaída en el Expediente N. ${ }^{\circ}$ 6534-2006-PA/TC. (2007). Tribunal Constitucional del Perú. Recuperado de https://tc.gob.pe/jurisprudencia/2008/065342006-AA.pdf

Sentencia recaída en el Expediente N. ${ }^{\circ}$ 0033-2010-AI/TC. (2012). Tribunal Constitucional del Perú. Recuperado de https://www.tc.gob.pe/jurisprudencia/2012/000332010-Al.html

Sentencia recaída en el Expediente N. ${ }^{\circ}$ 1470-2016-PHC/TC. (2019). Tribunal Constitucional del Perú. Recuperado de https://tc.gob.pe/jurisprudencia/2019/01470-2016-HC. pdf

Suárez Sebastián, M. P. (2009). Aspectos fundamentales de los DESC. En P. E. González Monguí (Coord.), Derechos económicos, sociales y culturales (pp. 61-111). Bogotá: Cátedra Gerardo Molina. 